\title{
Modulation of the Lobster Pyloric Rhythm by the Peptide Proctolin
}

\author{
Scott L. Hoopera and Eve Marder \\ Biology Department, Brandeis University, Waltham, Massachusetts 02254
}

The modulation of the pyloric network of the stomatogastric ganglion (STG) of the lobster Panulirus interruptus by the neuropeptide proctolin is described.

First, the effects of proctolin on the pyloric motor patterns were characterized in terms of frequency and phase relations. Pyloric cycle frequency and lateral pyloric (LP) neuron activity increased and ventricular dilator (VD) neuron activity decreased with increasing concentrations $\left(10^{-9}-10^{-6} \mathrm{M}\right)$ of applied proctolin. Next, the effects of proctolin on the individual neurons that constitute the pyloric network were determined. Identified neurons were isolated from chemical and electrical presynaptic inputs by using pharmacological agents (Marder and Eisen, 1984a) and/or photoinactivation following Lucifer yellow injection (Miller and Selverston, 1979). Proctolin increased the amplitude and frequency of bursts produced by isolated pacemaker anterior burster (AB) neurons. Isolated LP and pyloric (PY) neurons responded to proctolin with increases in activity only when they were at or above threshold. All other pyloric neurons were unaffected.

To determine how the direct effects of proctolin on isolated neurons resulted in the observed changes in frequency and phase relations in the motor pattern of the intact pyloric circuit seen in proctolin, individual neurons were deleted from the circuit. A comparison of proctolin's effects on isolated neurons with those on the intact network shows that the synaptic connectivity among neurons directly affected by proctolin and those unaffected by it shapes the network's response to proctolin.

Recent characterization and localization of neuropeptides throughout vertebrate and invertebrate nervous systems has revealed the diversity of signaling molecules used by the nervous system. Less is known about the mechanisms by which neuropeptides act; even less is known about how integrative actions of neural circuits are modulated or influenced by peptides. However, it is now clear that the output of neural networks can be varied and modulated by a variety of amines and peptides (Marder, 1984; Marder and Hooper, 1985; Flamm and Harris-Warrick, 1986a, b; Harris-Warrick, 1987). We have previously shown that the peptide proctolin modulates the pyloric rhythm of the

Received June 30, 1986; revised Jan. 26, 1987; accepted Jan. 27, 1987.

We thank Drs. J. Lisman, R. L. Calabrese, I. Levitan, M. P. Nusbaum, and Mr. J. Golowasch for helpful comments on earlier drafts of this manuscript Michael O'Neil gave us invaluable photographic and programming help, and Barbara Ayotte and Marcia Cabral assisted with manuscript preparation. Supported by NS 17813 .

Correspondence should be addressed to Dr. Eve Marder at the above address

a Present address: Laboratoire de Neurobiologie Comparée, CNRS, Université de Bordeaux, Arcachon, France 33120.

Copyright (c) 1987 Society for Neuroscience $0270-6474 / 87 / 072097-16 \$ 02.00 / 0$ stomatogastric ganglion (STG) (Hooper and Marder, 1984; Marder and Hooper, 1985; Marder et al., 1986). We now wish to explain how the proctolin-induced changes in the pyloric motor pattern can be accounted for on the basis of the actions of proctolin on the individual components of the pyloric network.

The pyloric rhythm of the STG of Panulirus interruptus is produced by a neural network consisting of one interneuron [the pacemaker anterior burster $(\mathrm{AB})$ neuron] and 13 motor neurons that innervate the striated muscles of the pyloric region of the lobster stomach. The pyloric network generates rhythmic motor patterns similar to those in the animal (Rezer and Moulins, 1983) even when isolated from sensory and central nervous system inputs (Selverston et al., 1976), and has been extensively studied as a model system of central pattern generation (Selverston et al., 1976; Hartline, 1979, 1987; Selverston and Miller, 1980; Miller and Selverston, 1982a, b; Miller, 1987). The pattern of synaptic connectivity among the pyloric neurons (Eisen and Marder, 1982) and many of their cellular properties are known (Raper, 1979a, b; Gola and Selverston, 1981; Russell and Hartline, 1982; Russell and Graubard, 1987). Movements of another region of the animal's stomach, the gastric mill, are controlled by another group of neurons found in the STG, those of the gastric mill network (Selverston et al., 1976). There are weak interactions between the pyloric and gastric rhythms (Mulloney, 1977).

The neuropeptide proctolin is found in many arthropod preparations (O'Shea and Schaffer, 1985). Although best known for its actions as a modulator at neuromuscular junctions (Lingle, 1979; Kravitz et al., 1980; Schwarz et al., 1980; Adams and O'Shea, 1983; Rane et al., 1984), proctolin is also found in many central neurons in crustaceans (Siwicki and Bishop, 1986). The neuropil of the STG of decapod crustaceans, including the crab Cancer borealis and the spiny lobster $P$. interruptus, is densely innervated by proctolin-containing projections of neurons with cell bodies in other ganglia (Hooper and Marder, 1984; Marder et al., 1986). We previously showed that bath-applied proctolin initiates rhythmic pyloric activity in quiescent STGs of C. borealis and increases the frequency of pyloric rhythms in slowly bursting crab and lobster preparations (Hooper and Marder, 1984; Marder and Hooper, 1985; Marder et al., 1986). In $P$. interruptus, proctolin applications can activate rhythmic gastric mill activity as well (Marder and Hooper, 1985; Heinzel and Selverston, 1985; Marder et al., 1986). Additionally, a proctolincontaining neuron that projects to the STG and influences pyloric motor patterns has been identified in C. borealis (Nusbaum and Marder, 1987). These data suggest that proctolin is an endogenously released modulator of the neuronal circuits found within the STG.

To better understand proctolin's effects on the pyloric network, we characterized in detail its effects on the pyloric rhythm of $P$. interruptus. By themselves, such data are insufficient to 
explain how these effects are produced, as changes in the firing patterns of a neuron in a network may either be a consequence of a direct action on that neuron or the result of changes in other neurons of the network. To resolve these issues, we first exploited the known pattern of synaptic connectivity of the pyloric network of $P$. interruptus (Eisen and Marder, 1982) to isolate individual pyloric network neurons from all chemical and electrical inputs from other pyloric network neurons. We then determined which of the pyloric network neurons responded directly to proctolin. A comparison of proctolin's effects on isolated neurons with those on the intact network clearly demonstrated that "circuit interactions" play an important role in proctolin's modifications of the pyloric motor output. A series of experiments in which various pyloric neurons were deleted from the network allowed us to determine which of the pyloric neurons were most important in causing these indirect effects of proctolin. Thus, we can reconstruct proctolin's effects on the pyloric network on the combined basis of its effects on isolated pyloric ncurons and of their synaptic connectivity. Preliminary reports of some of these data have appeared in abstract form (Hooper and Marder, 1985).

\section{Materials and Methods}

Animals. Panulirus interruptus were obtained from Marinus (Westchester, CA). Data in this paper were obtained from 90 male and female animals (250-750 gm). Animals were held in Instant Ocean seawater aquaria at $12^{\circ} \mathrm{C}$ for as long as 1 month.

Physiological saline. $P$. interruptus physiological saline had the following composition $\left(\mathrm{mm} /\right.$ liter): $\mathrm{NaCl}, 479 ; \mathrm{KCl}, 12.8 ; \mathrm{CaCl}_{2}, 13.7$; $\mathrm{Na}_{2} \mathrm{SO}_{4}, 3.9 ; \mathrm{MgSO}_{4}, 10$; Tris, 11 ; maleic acid, 4.8; pH 7.4-7.6. Dissections were performed in chilled saline, and all physiological experiments were carried out with continuously flowing superfusion $(8-10$ $\mathrm{ml} / \mathrm{min}$ ) of chilled saline $\left(12-14^{\circ} \mathrm{C}\right.$ ). Proctolin (Sigma, Peninsula Labs, or Bachem) was dissolved as a stock solution of $10^{-2} \mathrm{M}$ in distilled water. Dilutions from the stock were made to the desired concentration immediately before use. Proctolin-containing saline was introduced into the superfusion system without interrupting flow by means of a switching manifold. In some experiments $5 \times 10^{-6} \mathrm{M}$ picrotoxin (Sigma) was used to block glutamatergic IPSPs in the ganglion (Marder and Eisen, 1984a).

Physiology. Complete stomatogastric nervous systems [commissural ganglia (CGs), esophageal ganglion (EG), and STG with connecting nerves] were dissected as previously described (Mulloney and Selverston, 1974; Selverston et al., 1976). The STG was reversibly isolated from inputs from the anterior ganglia (CGs and EG) by placing a Vaseline well filled with isotonic sucrose $(750 \mathrm{~mm}$ ) on the desheathed stomatogastric nerve (STN). Occasionally the sucrose contained $10^{-6} \mathrm{M}$ TTX as well, but no differences in the efficacy of the block were observed when TTX was added. Recording techniques used were standard for this preparation (Mulloney and Selverston, 1974; Selverston et al., 1976; Eisen and Marder, 1982). Extracellular recordings from nerves were made using bipolar stainless steel pin electrodes insulated with Vaseline. Intracellular recordings from STG somata were made with glass microelectrodes with resistances of 20-50 M $\Omega$ filled with $2.5 \mathrm{M} \mathrm{KCl}$. Data were collected on an 8-channel Vetter FM tape recorder and then played back with an 8 -fold reduction of tape speed on a Gould 2400 chart recorder, or taken directly on the chart recorder.

Current-voltage curves. Manipulation of the membrane potential of neurons was carried out with 2 intracellular microelectrodes in each neuron studied. Current was passed using an active current clamp circuit. All I-V curves were made at steady-state levels after the membrane capacitance was charged by using pulses of approximately 100-200 msec, with long enough intervals to allow the decay of any activation or inactivation of voltage-dependent conductances that occurred during the test pulse.

Lucifer yellow photoinactivation. The neurons to be photoinactivated (Miller and Selverston, 1979) were filled intracellularly with Lucifer yellow $\mathrm{CH}$ (Sigma) and then photoinactivated by illumination with intense blue light using a WILD epifluorescence attachment on the dissecting microscope of the physiological setup. The criteria for pho- toinactivation were those of Miller and Selverston (1979; Selverston and Miller, 1980; Eisen and Marder, 1982; Miller and Selverston, 1982a, b). Subsequent to photoinactivation, the preparation was washed for at least $30 \mathrm{~min}$ prior to further physiological manipulations or measurements.

Phase-angle analysis. Phase analysis was carried out to determine the average percentage of a cycle at which any given neuron began and ended its burst. The beginning of a cycle (phase angle 0 ) was defined as the first action potential of the pyloric dilator (PD) neuron burst, and the end of a cycle (phase angle 1) as the first action potential of the next PD neuron burst. The cycle length was $t_{1}$, the number of seconds between 2 PD neuron bursts. The time of a given event after the beginning of a cycle was $t_{n}$, and the phase of that event was $t_{n} / t_{1}$. The process generally was repeated for 10 cycles, and the phase angles of an event in each burst were averaged to get the average phase angle of the event. This analysis normalizes with respect to frequency, allowing direct comparison of the phase relations of the pyloric motor neurons despite different cycle frequencies.

Statistics. Statistical tests were performed as described in Bruning and Kintz (1977). All $t$ tests were 2-tailed.

\section{Results}

The pyloric rhythm of the STG consists of a repeating sequence of alternating bursts of action potentials from the pyloric motor neurons. Figure 1 illustrates the pyloric rhythm from $P$. interruptus. Simultaneous intracellular recordings from the somata of 3 pyloric ncurons and extraccllular recordings from somc of the motor nerves of the STG are shown. The recordings in Figure 1 were taken from a preparation in which the EG and CGs were left attached. The resulting pyloric rhythm had a frequency of about $1.5 \mathrm{~Hz}$ and all classes of the pyloric motor neurons were firing action potentials.

The synaptic connectivity of the pyloric network is also shown in Figure 1. The generation of the pyloric rhy thm by the neurons of the pyloric network can be explained on the basis of the cellular properties of the individual neurons and their synaptic connectivity (Hartline, 1979; Hartline and Gassie, 1979; Miller and Selverston, 1982a, b; Russell and Hartline, 1982). In brief, the single $\mathrm{AB}$ interneuron rhythmically depolarizes and generates bursts of action potentials, thus serving as the pacemaker for the network. The two PD motor neurons depolarize synchronously with the $\mathrm{AB}$ neuron and generate bursts of action potentials as a result of the electrical coupling between the PD and $A B$ neurons. These 3 neurons inhibit the other pyloric neurons, which then fire out of phase with the $\mathrm{AB}-\mathrm{PD}$ neuron group. The ventricular dilator (VD) and lateral pyloric (LP) neurons inhibit each other, and generally fire at different times in a robustly active preparation (Fig. 1).

\section{Proctolin's effects on the pyloric rhythm}

When the inputs to the STG from the anterior CGs and EG are removed by blocking impulse traffic in the STN with a sucrose block, the pyloric rhythm always decreases in frequency and strength (Russell, 1976) and sometimes stops (Nagy and Miller, 1987). All the data reported in this paper were obtained with preparations in which the inputs from the anterior ganglia were blocked, as in Figure 2. After sucrose block, the frequency and vigor of the PD and VD neuron bursting were reduced (compare to Fig. 1), and the pyloric (PY), inferior cardiac (IC), and LP neurons were silent. (The PY and IC neurons almost always become silent after sucrose block, but the activity of the LP neuron is more variable, and often continues.) The effects of $10^{-6} \mathrm{M}$ proctolin on this preparation are shown in the bottom left panel of Figure 2. The frequency of the pyloric rhythm increased, the number of PD neuron action potentials per burst 


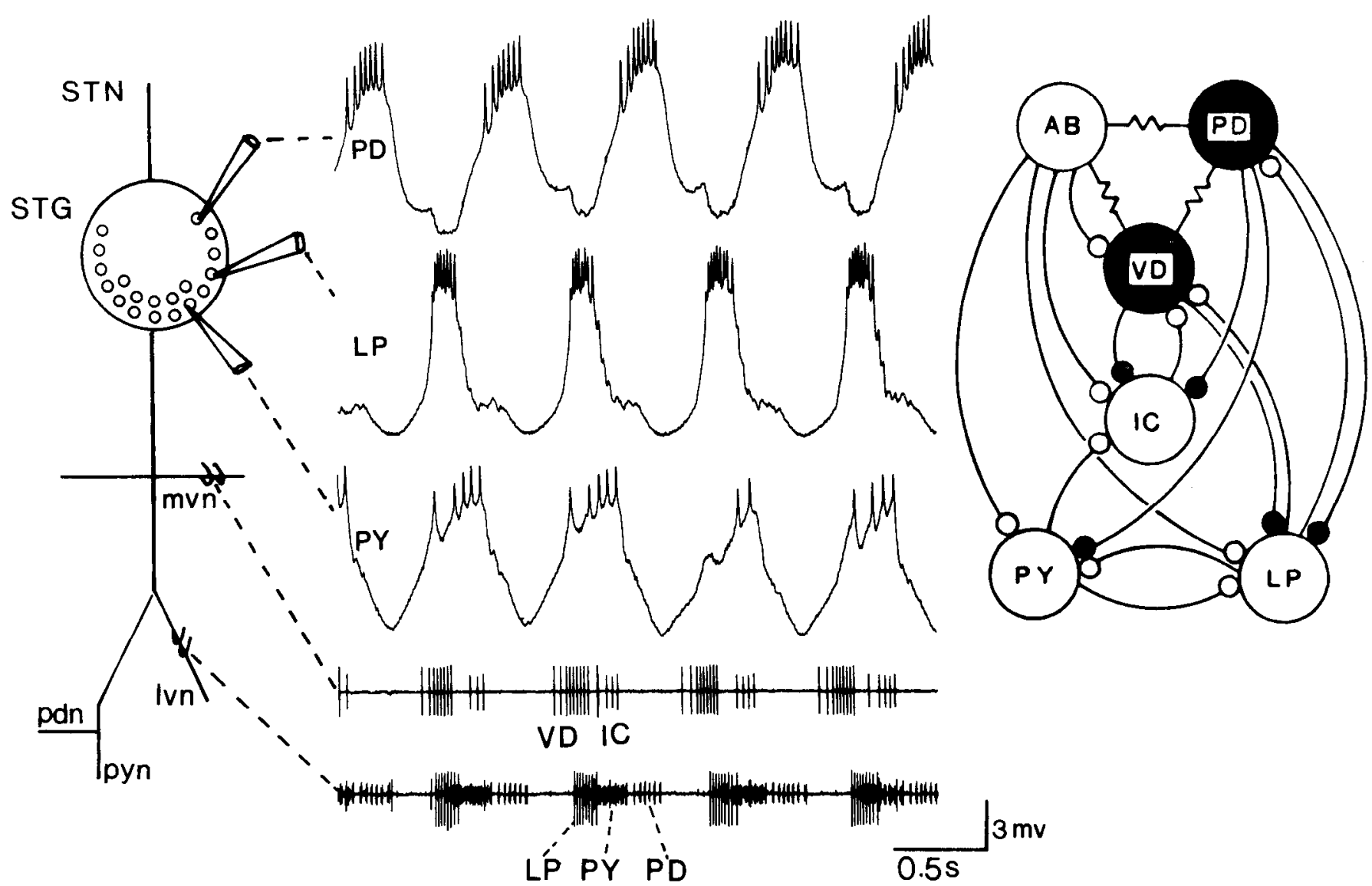

Figure 1. Pyloric system. Left, Schematic drawing of the isolated STG and motor ncrves showing position of recordings used in this paper. Pyloric motor pattern with the CGs and EG attached. Intracellular records taken from identified STG somata. The extracellular traces are taken from the median ventricular $(m v n)$ and the lateral ventricular $(l v n)$ nerves, on which can be seen the activities of all the pyloric motor neurons, as marked. Right, Synaptic connectivity of the pyloric network. Resistor symbols represent electrical coupling, small circles inhibitory chemical synapses. The glutamatergic neurons and synapes are white, the cholinergic neurons and synapses are black. Connectivity diagram is modified from that in Marder and Eisen (1984a). The AB neuron IPSP onto the inferior cardiac (IC) neuron has been added, since we have demonstrated that it remains after photoinactivating the PD and VD neurons. Not shown is the electrical coupling between some of the PY neurons and the LP neuron (Hartline and Gassie, 1979; Hartline et al., 1986, 1987).

increased greatly, the VD neuron fired fewer action potentials per burst, and the LP neuron started to fire robust bursts of action potentials. Neither the IC nor the PY neurons were activated.

To compare directly the pyloric rhythms in the presence and absence of proctolin, despite the proctolin-induced change in pyloric cycle frequency, we normalized the data and performed a phase analysis (see Materials and Methods). The results of such analysis, when applied to the raw data shown in the left panels of Figures 2, are shown in the right panels of Figure 2. In saline the PD neuron fired from phase angles $0-0.16$ and the VD neuron from $0.22-1.04$ (slightly overlapping the beginning of the next PD neuron burst). In proctolin the PD neuron was active for a slightly longer percentage of the cycle (phase angles $0-0.22$ ) and the proctolin-activated LP neuron was active from phase angles $0.46-0.93$. In proctolin the VD burst was reduced as a percentage of the cycle length, starting later and ending earlier (phase angles 0.54-0.94).

To quantify the effects of proctolin on the pyloric rhythm, we collected data from 12 preparations, using only extracellular recordings in order to avoid damaging the neurons. These preparations gave stable baselines over many hours, and allowed us to compare the effects of more than one proctolin concentration on the same preparation after extensive washing. Table 1 shows the effect of proctolin on the frequency of the pyloric rhythm in saline, $10^{-8}, 10^{-7}$, and $10^{-6} \mathrm{M}$ proctolin. Proctolin increased the frequency of these slowly cycling preparations in a dosedependent manner. The threshold for the proctolin effect was around $10^{-9} \mathrm{M}$. A $30 \%$ increase in cycle frequency was produced by $10^{-8} \mathrm{M} ; 10^{-7} \mathrm{M}$ proctolin produced a $52 \%$ change, and $10^{-6}$ M proctolin produced a $58 \%$ change. Each of these changes was statistically significant (see Table 1, legend). The values shown in Table 1 underestimate the effect proctolin can have on the frequency of the pyloric rhythm, since the maximum pyloric frequency seen in proctolin was about $1 \mathrm{~Hz}$ (Table 1; see last section of Results). When proctolin was applied to very slowly cycling preparations, it produced a much larger percentage increase than when applied to more active preparations. When proctolin was applied to preparations cycling more rapidly than $1 \mathrm{~Hz}$, there was either no change in pyloric frequency or a slight decrease was seen.

The effects of proctolin on the phase relations of the pyloric neurons are shown in Figure 3, in which data are pooled from the same 12 preparations used for Table 1 . These phase plots show the following: (1) Proctolin increased the length of the LP neuron burst, causing the LP neuron to start firing earlier and end later in the cycle than in saline. This increase in LP burst length was associated with an increase in the number of LP 


\section{CONTROL}

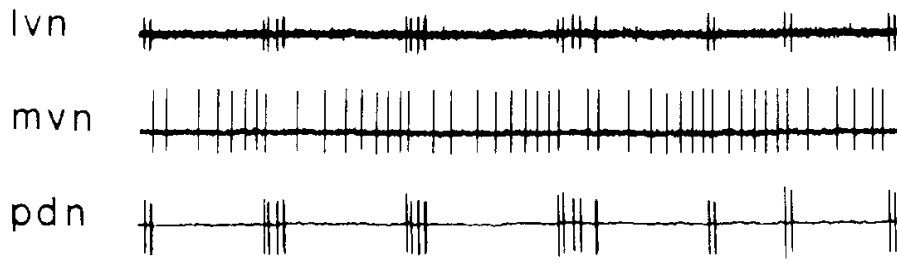

pyn

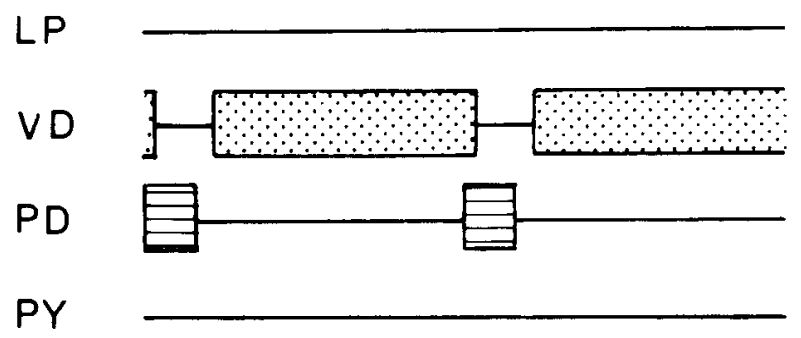

\section{$10^{-6} \mathrm{M}$ PROCTOLIN}

$\operatorname{lvn}$

$m \vee n$

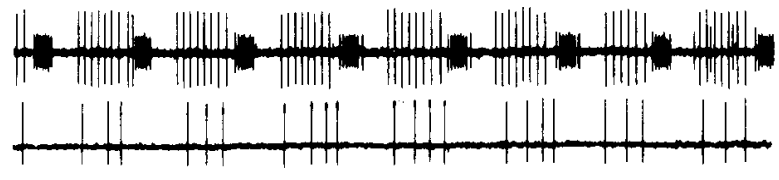

pdn

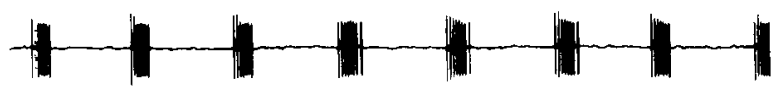

pyn

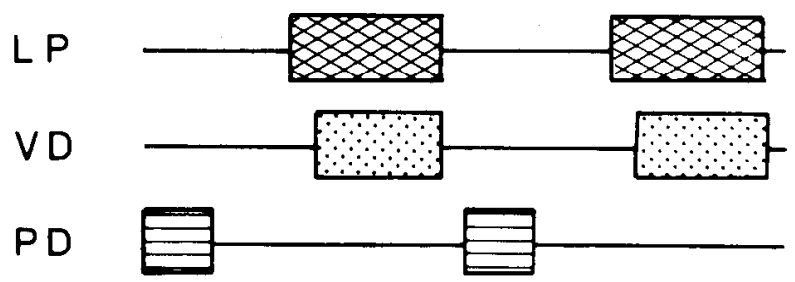

PY

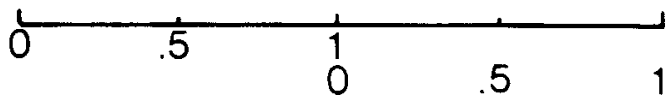

Figure 2. Effects of proctolin on the pyloric rhythm. Left, Extracellular recordings from the lvn, mvn. pyloric dilator nerve (pdn), and pyloric nerve (pyn). Top, Activity in control saline; bottom, activity in $10^{-6} \mathrm{M}$ proctolin. LP neuron activity can be seen on the lvn (large units, bottom panel), PD neuron activity on the lvn (small units) and on the pdn, VD neuron activity on the mvn (the IC neuron is silent throughout), and PY neuron activity on the pyn (also silent throughout). Right, Phase-normalized plots of the data shown on the left side. The percentage of the cycle length at which each neuron begins and ends its burst of action potentials in saline and in $10^{-6} \mathrm{M}$ proctolin is shown as marked. Two cycles of the pattern are plotted to emphasize the rhythmically repeating nature of the pyloric motor output.

neuron spikes per burst as well (Table 2). (2) Proctolin resulted in a retardation of the beginning of the VD neuron burst, with a consequent shortening of the VD neuron burst length (Fig. 3). The decrease in VD burst length was associated with a decrease in the number of VD neuron spikes per burst (Table 2).

An additional effect of proctolin can be seen only in intracellular recordings. Figure 4 shows simultaneous intracellular recordings from the $\mathrm{AB}, \mathrm{VD}$, and $\mathrm{LP}$ neurons in saline and in $10^{-6} \mathrm{M}$ proctolin, and demonstrates a marked increase in the amplitude of the membrane potential oscillations of the $A B$ neuron in the presence of $10^{-6} \mathrm{M}$ proctolin. Recordings from PD neurons revealed similar increases in the amplitude of their membrane potential oscillations. The amplitude of the membrane potential oscillations of the $\mathrm{AB}$ and $\mathrm{PD}$ neurons increased in proctolin from $4.7 \pm 4.1$ to $9.3 \pm 4.7 \mathrm{mV}(n=9)$ and from $6.3 \pm 3.6$ to $9.8 \pm 3.3 \mathrm{mV}(n=36)$, respectively. These increases are significant at the $p<0.005$ and $p<0.001$ levels, respectively (repeated-measures ANOVA).

We have previously shown that proctolin induced pyloric cycling in quiescent STG from the crab C. borealis (Hooper and Marder, 1984; Marder and Hooper, 1985). Figure 5 shows that proctolin application evoked rhythmic pyloric rhythms in quiescent STG in $P$. interruptus. The application of proctolin induced vigorous bursting, although without any dramatic change in the $\mathrm{PD}$ or $\mathrm{AB}$ neuron's baseline membrane potential.

The effects of proctolin outlasted the presence of proctolin in the bathing solution. The effects of a 5-10 min application of $10^{-7}$ or $10^{-6} \mathrm{M}$ proctolin were reversed only after a 30-60 min washing in control saline. The effects of shorter applications of lower concentrations of proctolin washed out more rapidly, but in all cases at least $15 \mathrm{~min}$ of washing were required. No evidence of desensitization during a proctolin application was seen.

\section{Proctolin's effect on isolated pyloric neurons}

The first step toward understanding how proctolin induces these changes in the pyloric motor pattern was to determine which of the pyloric neurons respond directly to proctolin applications. Because of the complicated synaptic connectivity of the pyloric network (Fig. 1), changes in the activity of a neuron do not mean that that neuron is directly affected by proctolin, but could be a consequence of "circuit" interactions.

It is possible to isolate individual pyloric network neurons from all interactions with other pyloric neurons by means of a combination of presynaptic neuron deletion and pharmacological blockade (Marder and Eisen, 1984b; Flamm and HarrisWarrick, 1986a, b). The glutamatergic chemical synapses of the 


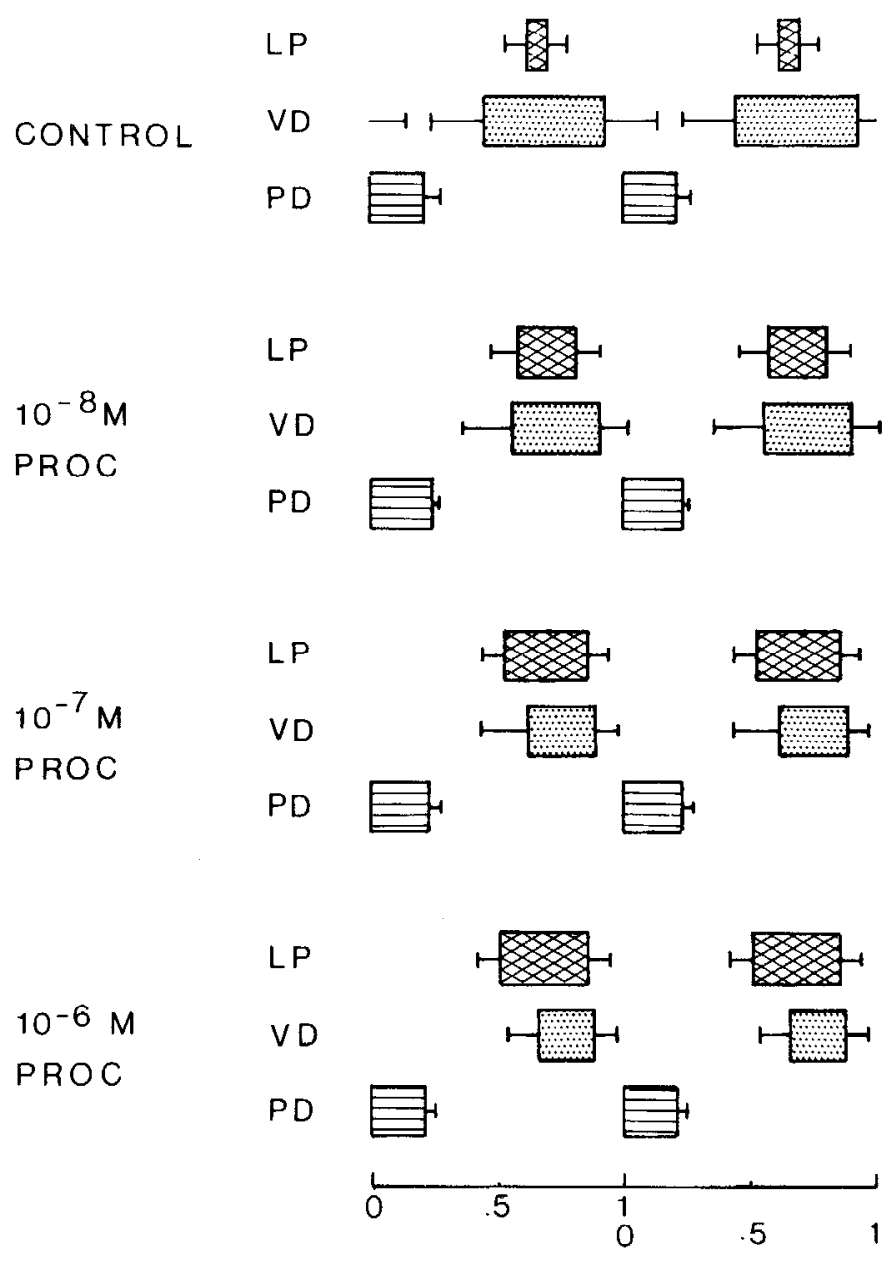

Figure 3. Concentration dependence of proctolin's effects on the pyloric pattern. Panels show average phase-angle plots of the activity of the pyloric motor neurons. Saline (first panel; $n-12$ ); $10^{-8} \mathrm{M}$ proctolin (second panel; $n=6$ ); $10^{-7} \mathrm{M}$ proctolin (third panel; $n=5$ ); $10^{-6} \mathrm{M}$ proctolin (fourth panel; $n=10$ ). A continuous increase in LP neuron activity and decrease in VD neuron activity is seen with increasing proctolin concentration. Error bars are \pm SDs. The onset of LP neuron activity in proctolin, compared to saline, is different in $10^{-7} \mathrm{M}$ proctolin at $p<0.05$, and in $10^{-6} \mathrm{M}$ proctolin at $p<0.01$. The end of the LP neuron burst is different from saline at $p<0.01$ in $10^{-7} \mathrm{M}$ proctolin and at $p<0.001$ in $10^{-6} \mathrm{M}$ proctolin. The beginning of the VD neuron burst is different from saline at the $p<0.02$ level in $10^{-6} \mathrm{M}$ proctolin (Student's $t$ test). To minimize damage, experiments used to generate these data were carried out using extracellular recordings without penetrating the neurons with intracellular electrodes. Preparations were extensively washed between applications. We found that control baseline conditions were stable over many hours in the absence of intracellular recordings.

AB, LP, PY, and IC neurons (see Fig. 1) can be blocked by low $\left(5 \times 10^{-6} \mathrm{M}\right)$ picrotoxin (PTX) concentrations (Bidaut, 1980; Eisen and Marder, 1982; Marder and Eisen, 1984a). Any one of the electrically coupled $\Lambda \mathrm{B}, \mathrm{PD}$, and VD neurons can bc isolated from the others by photoinactivating the other neurons subsequent to Lucifer yellow injection (Eisen and Marder, 1982, 1984; Miller and Selverston, 1982a; Marder and Eisen, 1984b). Cholinergic synaptic input to a given postsynaptic neuron can be abolished by photoinactivation of the presynaptic neuron. These techniques were used to isolate each of the different classes of pyloric neurons from all other pyloric inputs. We then studied the effects of proctolin on each class of neuron.

\begin{tabular}{|c|c|c|}
\hline $\begin{array}{l}\text { Concentration } \\
\text { (M) }\end{array}$ & $\begin{array}{l}\text { Frequency } \\
(\mathrm{Hz})\end{array}$ & $n$ \\
\hline Saline & $0.60 \pm 0.15$ & 12 \\
\hline $10^{-8}$ & $0.78 \pm 0.19^{*}$ & 6 \\
\hline $10^{-7}$ & $0.91 \pm 0.2^{* *}$ & 5 \\
\hline $10^{-6}$ & $0.95 \pm 0.14^{* * *}$ & 10 \\
\hline
\end{tabular}

Values (means $\pm \mathrm{SD}$ ) are statistically significant when compared to saline, as indicated. ${ }^{*} p<0.05 ;{ }^{* *} p<0.01 ;{ }^{* * *} p<0.001$ (Student's $t$ test).

$A B$ neuron. Experiments on isolated $\mathrm{AB}$ neurons clearly showed that proctolin increased the frequency and amplitude of the $\mathrm{AB}$ neuron bursts. In the experiment shown in Figure 6 , $10^{-6} \mathrm{M}$ proctolin increased the frequency of the $\mathrm{AB}$ neuron burst from 0.36 to $2.2 \mathrm{~Hz}$ and increased the amplitude of the $\mathrm{AB}$ neuron slow membrane potential oscillation from 10 to $24 \mathrm{mV}$. The administration of $10^{-8} \mathrm{M}$ proctolin resulted in almost equivalent increases $\left(90 \%\right.$ of the $10^{-6} \mathrm{M}$ values), suggesting that the $\mathrm{AB}$ neuron response to $10^{8} \mathrm{M}$ proctolin is near maximal. In 9 experiments on isolated $\mathrm{AB}$ neurons, proctolin increased the frequency $101 \pm 54 \%$ (mean $\pm \mathrm{SD}$ ). The average burst frequency of isolated $\mathrm{AB}$ neurons in proctolin was $2.13 \pm 0.23$ $\mathrm{Hz}$, and the maximum frequency achieved by isolated $\mathrm{AB}$ neurons in the presence of proctolin was $2.8 \mathrm{~Hz}$.

$P D$ and VD neurons. Isolated PD and VD neurons were insensitive to proctolin by several criteria. Figure 7 shows simultaneous intracellular recordings from the 2 isolated PD neurons in saline and in $10^{-6} \mathrm{M}$ proctolin. This experiment shows that the tonic activity in these neurons was not influenced by proctolin application. Current-voltage curves of isolated PD and VD neurons were also unaffected by the application of proctolin (data not shown). In 5 experiments on isolated PD neurons and in 4 experiments on isolated VD neurons, no effect of proctolin was seen.

LP neuron. Figure 8 shows that proctolin (triangles) depolarized and excited isolated LP neurons in a dose-dependent manner. After each application, the preparation was washed until the neuron had returned to control levels of activity. The LP neuron activity continually increased with increasing proctolin concentration throughout this range of concentrations. The depolarizations produced by proctolin were modest $(2-3 \mathrm{mV}$ at most), but the increase in firing frequency was often substantial (18-fold in the experiment shown here). In 7 experiments on isolated LP neurons, the depolarization produced by $10^{-6} \mathrm{M}$ proctolin was $2.7 \pm 1.5 \mathrm{mV}$ (mean $\pm \mathrm{SD}$ ) and the increase in frequency was $6.6 \pm 4.5 \mathrm{~Hz}$.

The action of proctolin on LP neurons was dependent on the membrane potential of the neuron. That is, the excitatory proc-

\begin{tabular}{llll}
\hline Table 2. & Number of spikes/burst in proctolin & \\
& $\begin{array}{l}\text { Control } \\
(n=15)\end{array}$ & $\begin{array}{l}10^{-7} \mathbf{M} \\
(n=5)\end{array}$ & $\begin{array}{l}10^{-6} \mathbf{M} \\
(n=10)\end{array}$ \\
\hline LP & $1.5 \pm 2.8$ & $4.8 \pm 3.1^{*}$ & $6.3 \pm 4.2^{* * *}$ \\
PD & $6.2 \pm 2.3$ & $7.6 \pm 1.1$ & $6.5 \pm 1.7$ \\
VD & $8.4 \pm 10.1$ & $3.7 \pm 3.8$ & $2.5 \pm 2.6^{* *}$
\end{tabular}

Values (means \pm SD) were statistically significant compared to controls using related-measures $t$ test. ${ }^{*} p<0.01 ;{ }^{* *} p<0.002 ;{ }^{* * *} p<0.001$. 


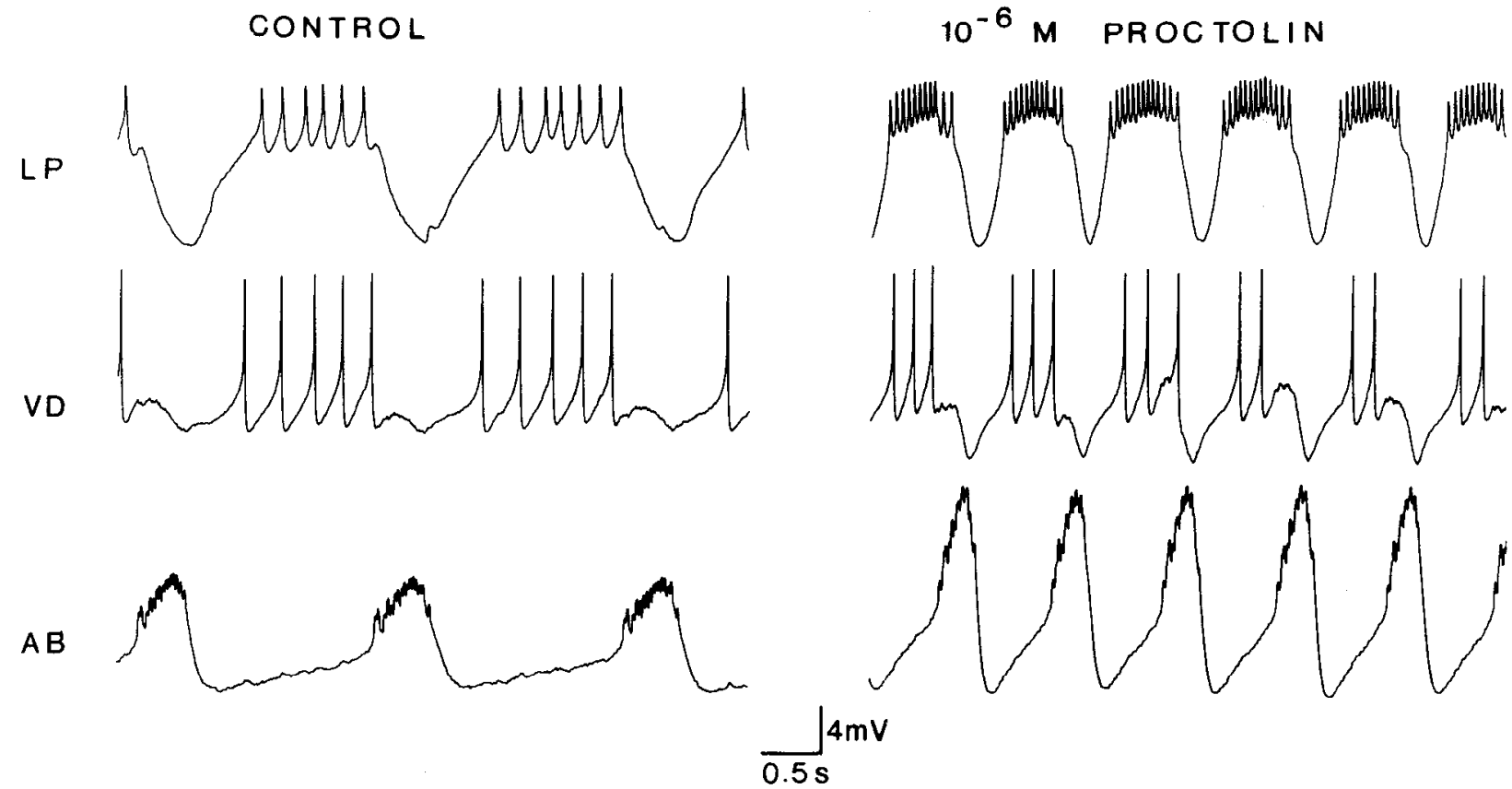

Figure 4. Proctolin increases the amplitude of the AB neuron membrane potential oscillations. In both panels, simultaneous intracellular recordings from the same LP, VD, and AB neurons are shown. Left, Saline; right, $10^{-6} \mathrm{M}$ proctolin. The most hyperpolarized points of the membrane potential of the neurons are as follows. Saline: LP neuron, $-30 \mathrm{mV}$; VD neuron, $-54 \mathrm{mV}$; AB neuron, $-42 \mathrm{mV}$. $10^{-6} \mathrm{M}$ proctolin: LP neuron, $-30 \mathrm{mV}$; VD neuron, $-58 \mathrm{mV}$; $\mathrm{AB}$ neuron, $-40 \mathrm{mV}$.

tolin action was only expressed when the LP neuron was close to or at threshold, as shown in Figure 9. In the absence of injected current, this cell's baseline membrane potential was -52 to -54 $\mathrm{mV}$, and proctolin produced a 3-4 $\mathrm{mV}$ depolarization and increase in firing frequency (Fig. 8). When the LP neuron was hyperpolarized to $-58 \mathrm{mV}$, proctolin application still elicited a dcpolarization and high-frequency firing (Fig. 9). However, when the LP neuron was hyperpolarized further to $-62 \mathrm{mV}$, proctolin application induced neither a change in membrane potential nor firing. In other experiments, the membrane potential of isolated LP neurons was manipulated throughout the range of potentials from -110 to $-20 \mathrm{mV}$. In all cases, proctolin
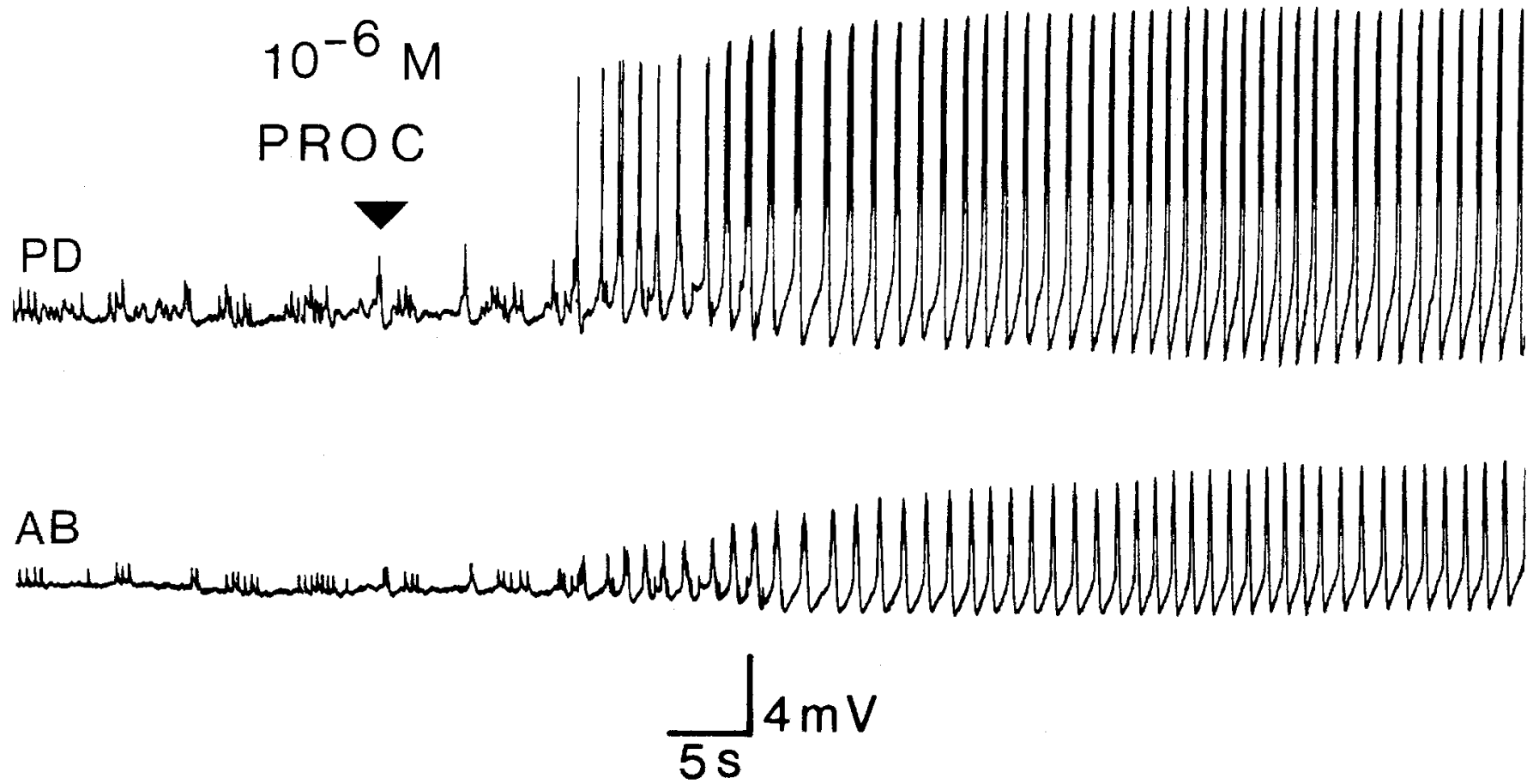

Figure 5. Proctolin can induce rhythmic activity in quiescent preparations. Simultaneous intracellular recordings from a PD and an AB neuron are shown. Proctolin $\left(10^{-6} \mathrm{M}\right)$ was applied at the triangle. The membrane potentials of the neurons before proctolin was applied were $-60 \mathrm{mV}$ (PD neuron) and $-54 \mathrm{mV}$ (AB neuron). 


\section{PROCTOLIN ON ISOLATED AB NEURON}
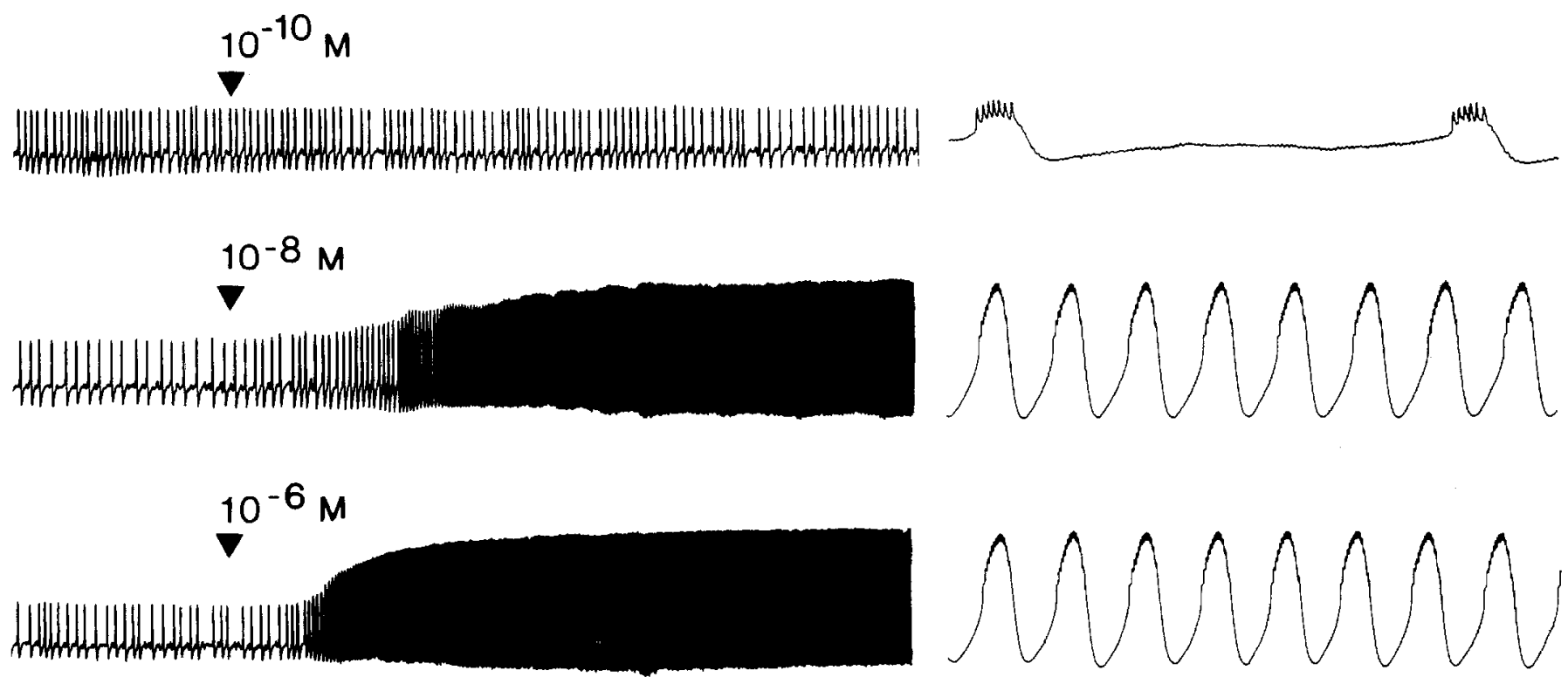

$10 \mathrm{mV}$

\section{$\overline{20 \mathrm{~s}} \quad \overline{0.4 \mathrm{~s}}$}

Figure 6. Proctolin excites the $\mathrm{AB}$ neuron in a dose-dependent manner. All traces are intracellular recordings from the same neuron, onto which increasing concentrations of proctolin were bath-applied (triangles). Between applications, the preparation was washed with control saline (at least $45 \mathrm{~min}$ ) until the $\mathrm{AB}$ neuron activity returned to saline values. Note that the left traces are at a slow chart speed and show the developing response; the right traces are at a higher chart speed and show the response when fully expressed. The AB neuron was isolated from other pyloric synaptic input by photoinactivating the PD and VD neurons. The most hyperpolarized points of membrane potential of the neuron before proctolin application were as follows: $-55 \mathrm{mV}\left(10^{-10} \mathrm{M}\right.$ proctolin), $-57 \mathrm{mV}\left(10^{-8} \mathrm{M}\right.$ proctolin), $-56 \mathrm{mV}\left(10^{-6} \mathrm{M}\right.$ proctolin).

effects were only seen at membrane potentials close to (within 2-3 $\mathrm{mV}$ of) and more depolarized than threshold. In spite of the large increase in firing frequency produced by proctolin application, we were unable to measure changes in the steady-state current-vollage curves obtained with 2 electrodes in the cell body (data not shown), presumably because of the electrotonic distance between the cell body recording and current-passing electrodes and the neuropil.

$P Y$ neurons. There are $8 \mathrm{PY}$ neurons in the $P$. intermptus STG. Extracellular recordings from the pyn failed to show activation of PY neurons by proctolin (Fig. 2). We were, however, concerned that some change in their activity that could only be seen in intracellular recordings might be induced by proctolin. Furthermore, while these neurons have been roughly divided into 2 classes, the PY early (PE) and PY late (PL) neurons (Hartline and Gassie, 1979; Hartline et al., 1987), individual PY neurons within these classes are not uniquely identifiable. It was thus possible that PY neurons might differ in their response to proctolin, and that proctolin might affect only one or a few of the PY neurons. Therefore, we recorded from as many PY neurons as possible in intact pyloric networks in several preparations to look for any indication of PY neuron response to proctolin. Results of such an experiment are shown in Figure $10 \mathrm{~A}$, which shows simultaneous intracellular recordings from 4 PY neurons. None of these was firing under control conditions; each was rhythmically hyperpolarized during the $A B / P D$ phase of the pyloric rhythm. In the presence of $10^{-6} \mathrm{M}$ proctolin, none of the PY neurons was activated, although proctolin did increase the pyloric frequency (shown in Fig. $10 \mathrm{~A}$ by the increased fre- quency of the AB/PD neuron-induced IPSPs). In 3 preparations in which we recorded from multiple PY neurons (a total of 13 PY neurons), only one PY neuron responded to proctolin by firing action potentials. In this case the neuron had probably been damaged and was therefore depolarized (see below). The failure to see PY neuron activation in either extracellular or intracellular recordings argues that none of the PY neurons is activated to fire action potentials by proctolin application in sucrose-blocked, isolated STGs showing moderate or low levels of pyloric activity.

Despite these negative results, we studied the responses of isolated PY neurons to proctolin application. All such neurons were below threshold at their resting potential, and no change in their membrane potential, activity, or current-voltagc rclationship was measured ( $n=5$; data not shown). However, when sufficient depolarizing current was injected into PY neurons ( $n=$ 6) to cause them to fire (Fig. 10B), $10^{-6} \mathrm{M}$ proctolin produced a slight depolarization and increase in action potential frequency.

IC neuron. In 3 out of 4 cases proctolin produced no effect on isolated IC neurons. In one case, a low-frequency oscillation was seen, which may have been due to activation of the gastric system (see Discussion). No change in the input impedance of IC neurons was seen in I-V curves (data not shown).

All the previous results were obtained from neurons isolated from all known electrical and chemical interactions with other pyloric neurons. However, nerve terminals from other neurons in the neuropil of the STG remain, which could be the target of proctolin action. Proctolin actions on isolated AB and LP 


\section{CONTROL}
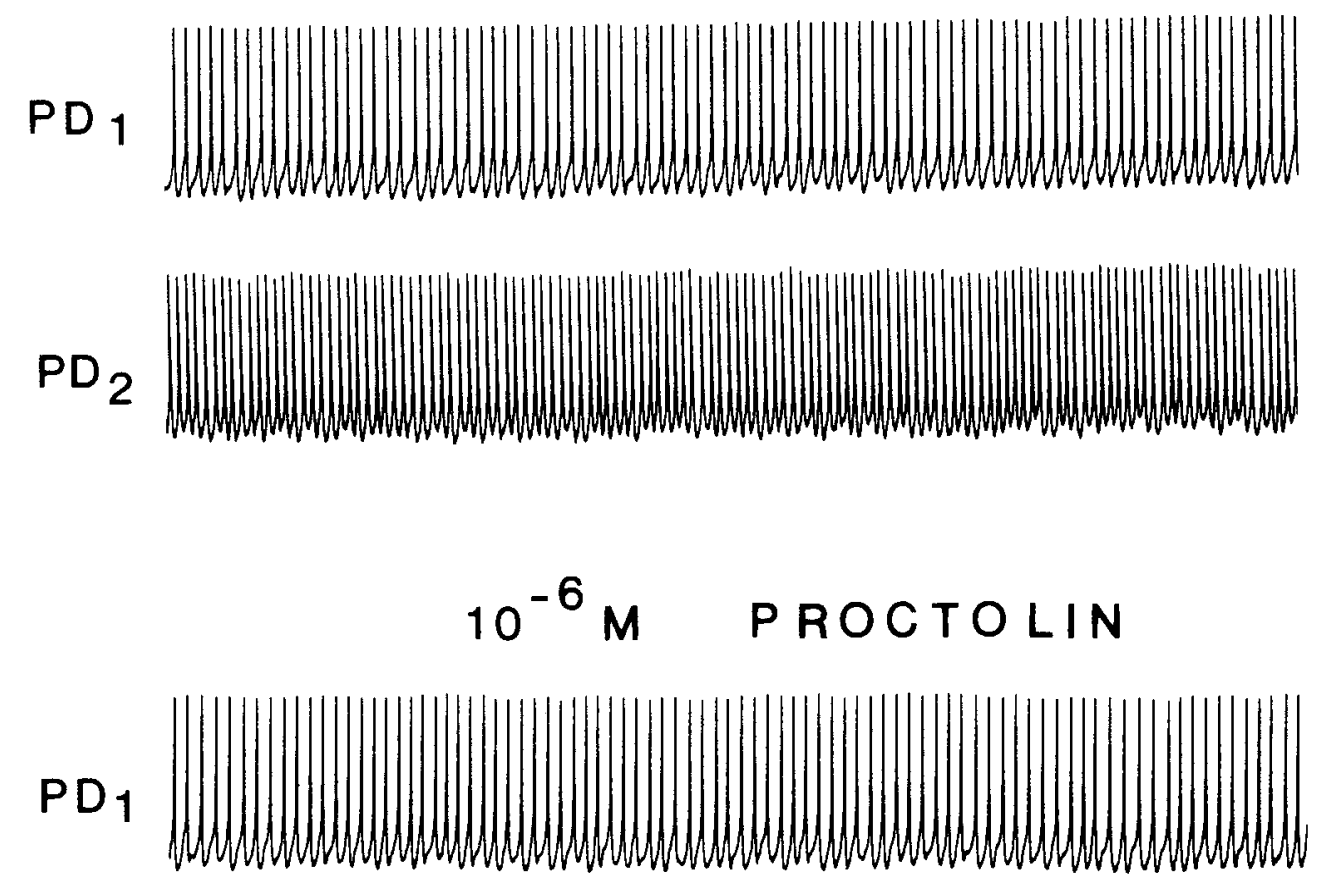

Figure 7. Isolated PD neurons were not affected by proctolin. Intracellular recordings from 2 PD neurons in a preparation in saline and $10^{-6} \mathrm{M}$ proctolin. The most hyperpolarized point of membrane potential of both of these neurons in both conditions was -47 $\mathrm{mV}$. PD neurons were isolated by photoinactivating the $\mathrm{AB}$ and $\mathrm{VD}$ neurons and applying $5 \times 10^{-6} \mathrm{M}$ PTX containing saline to block the LP-PD neuron glutamatergic synapse.

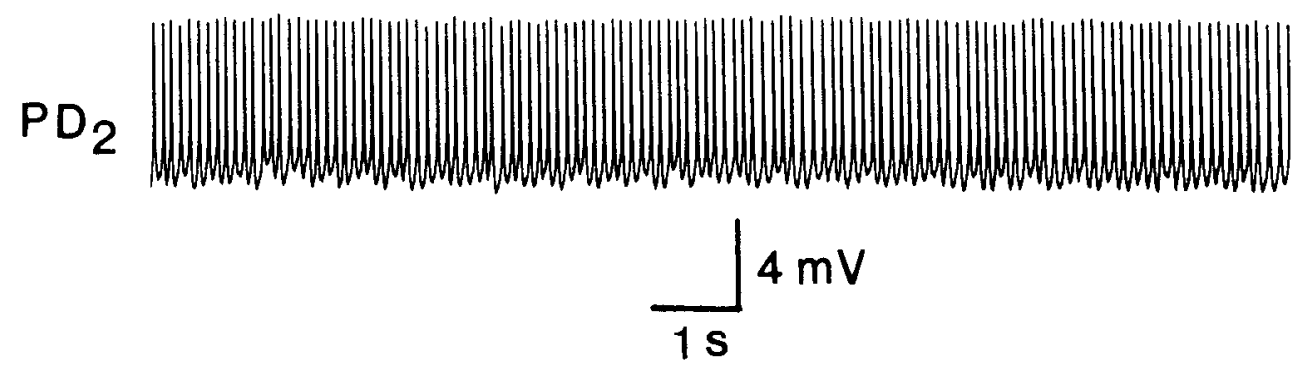

neurons and on the intact circuit were abolished in the presence of $10^{-6} \mathrm{M}$ TTX or $20 \mathrm{~mm} \mathrm{MnCl}_{2}$, although proctolin actions persist in TTX in C. borealis (J. Golowasch and E. Marder, unpublished observations). Since the action of proctolin is likely to involve the modulation of voltage-dependent conductances that may require $\mathrm{Ca}^{2+}$ and TTX-sensitive $\mathrm{Na}^{+}$currents for expression, the data presented here are not inconsistent with a direct action of proctolin on the $\mathrm{AB}, \mathrm{LP}$, and PY neurons. However, we cannot rule out the possibility that proctolin acts on some unknown presynaptic terminal that releases an unknown substance in a dose-dependent manner and acts specifically on the $A B, L P$, and PY neurons.

\section{Reconstruction of proctolin's effects}

Can the effects of proctolin on isolated neurons explain the changes it produces in the pyloric motor patterns? Certain of proctolin's effects on the intact network are consistent with its effects on the isolated neurons and on the properties of the pyloric network's synaptic connectivity. In particular, proctolin's direct actions on the isolated AB neuron can explain the increase that proctolin induces in the frequency and amplitude of the membrane potential oscillations of the $\mathrm{AB}$ neuron in the intact network. The increased amplitude of the PD neuron's membrane potential oscillations seen in proctolin in the intact network can also be explained by proctolin's direct actions on the $A B$ neuron because of the electrical coupling between the $P D$ and $A B$ neurons. The increase in LP neuron firing seen in proctolin in the intact network is consistent with proctolin's direct excitatory actions on the LP neuron.

However, 2 features of the actions of proctolin on the intact network are somewhat puzzling and require further explanation: (1) Proctolin does not act directly on the VD neuron, but the phase of the beginning of the VD neuron burst is retarded when proctolin is applied to the intact network. (2) In the presence of proctolin the isolated $\mathrm{AB}$ ncuron bursts as fast as $2.8 \mathrm{~Hz}$, but the intact network cycles only up to $1-1.1 \mathrm{~Hz}$ in the presence of proctolin. The following series of experiments were designed to help explain these 2 findings.

$V D$ phase retardation. If the VD neuron always fired with a fixed time delay after the firing of $\mathrm{PD}$ and $\mathrm{AB}$ neurons regardless of pyloric frequency - since proctolin increases the frequency of the pyloric rhythm-this would result in an apparent phase retardation of the VD neuron. However, the VD neuron does not fire at a fixed delay after the end of the PD neuron burst. Instead, in the 12 preparations used in Figure 3 and Tables 1 and 2 , the mean delay after the end of the PD burst until the beginning of the VD neuron burst was $0.32 \mathrm{sec}$ in saline, 0.31 sec in $10^{-8} \mathrm{M}$ proctolin, $0.40 \mathrm{sec}$ in $10^{-7} \mathrm{M}$ proctolin, and 0.46 sec in $10^{-6} \mathrm{M}$ proctolin. Thus the VD neuron both fires later in proctolin in real time and is retarded in phase. 

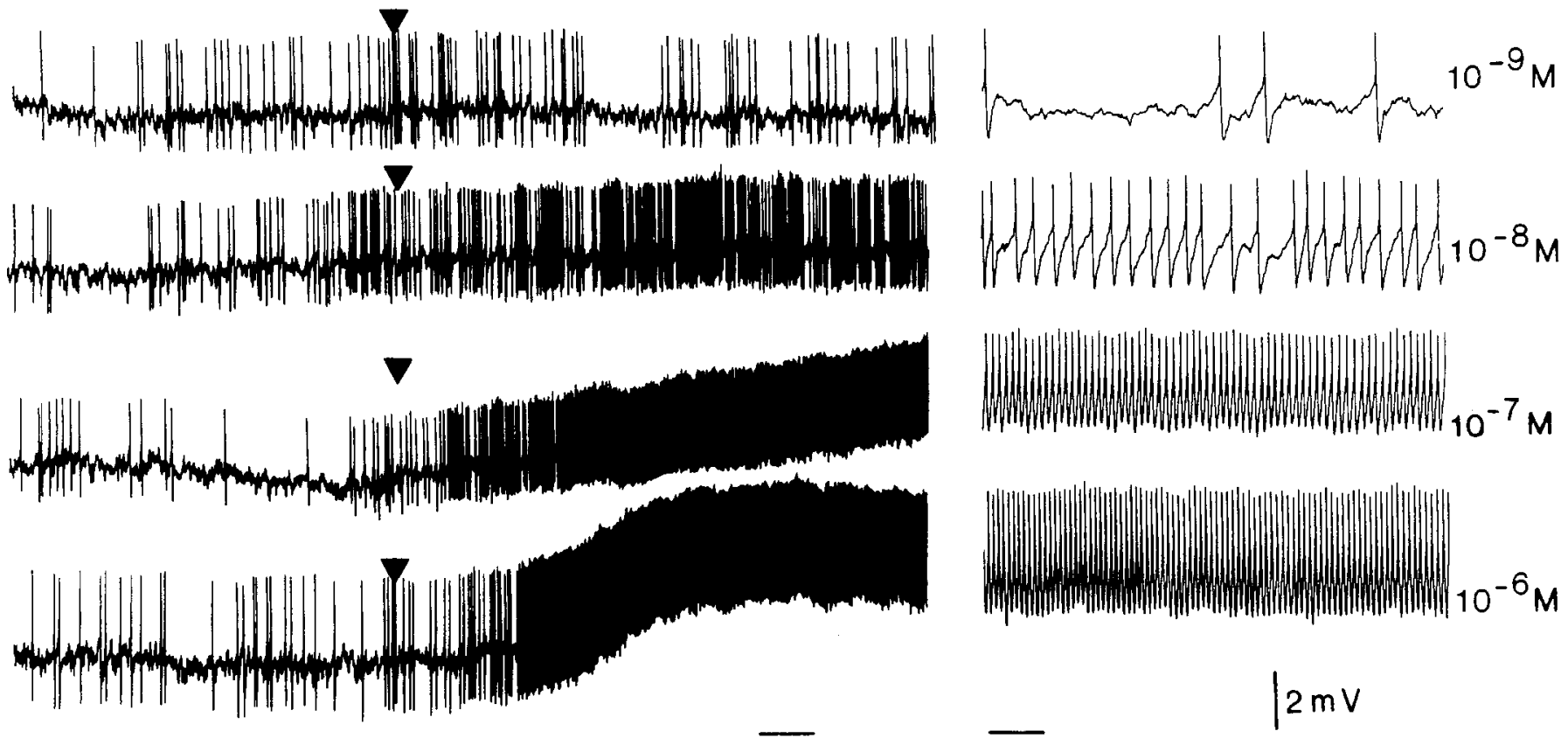

$10 \mathrm{~s}$

$1 \mathrm{~s}$

Figure 8. Proctolin increased isolated LP neuron activity in a dose-dependent manner. All traces are intracellular recordings from the same neuron onto which increasing concentrations of proctolin were bath-applied (triangles). Between applications, the preparation was washed with control saline (at least $45 \mathrm{~min}$ ) until the LP neuron activity returned to saline values. Note that the left traces are at a slow chart speed and show the developing response; the right traces are at a higher chart speed and show the response when fully expressed. LP neuron was isolated by photoinactivating the VD and PD neurons and applying $5 \times 10^{-6} \mathrm{M}$ PTX containing saline to block the PY and AB-LP neuron glutamatergic synapses. The most hyperpolarized points of membrane potential of the neuron before proctolin application were as follows: $-54 \mathrm{mV}\left(10^{-9}, 10^{-8}\right.$, and $10^{-7}$ $\mathrm{M}$ proctolin), and $-52 \mathrm{mV}\left(10^{-6} \mathrm{M}\right.$ proctolin).

The phase retardation of the beginning of the VD neuron burst seen in proctolin could be due to increased inhibition from the more active LP neuron and/or to increased inhibition from the increased frequency and activity of the $\mathrm{AB}$ neuron (see Fig.
1). Both manipulations and deletions of the LP neuron suggested that it alone was insufficient as an explanation of the VD phase retardation seen in proctolin. The LP-deletion experiment shown in Figure 11 illustrates this. This experiment was particularly

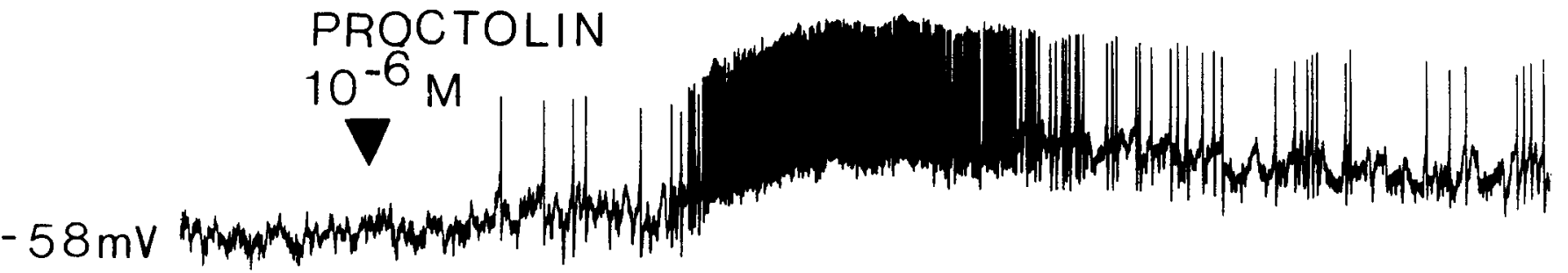

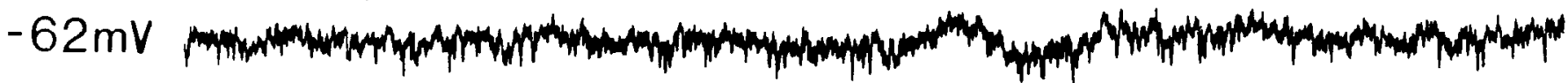

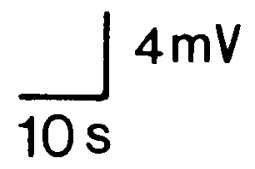

Figure 9. Expression of proctolin's effects on the isolated LP neuron depends on the neuron's membrane potential. Two microelectrodes were placed in the neuron, one to measure membrane potential, while current was passed with the other. When the neuron was hyperpolarized to -58 $\mathrm{mV}$ and proctolin applied (triangle), the LP neuron depolarized and began to fire action potentials (top trace). When the LP neuron was hyperpolarized to $-62 \mathrm{mV}$, it failed to depolarize or fire in response to proctolin application (bottom trace). Same neuron as in Figure 8. 


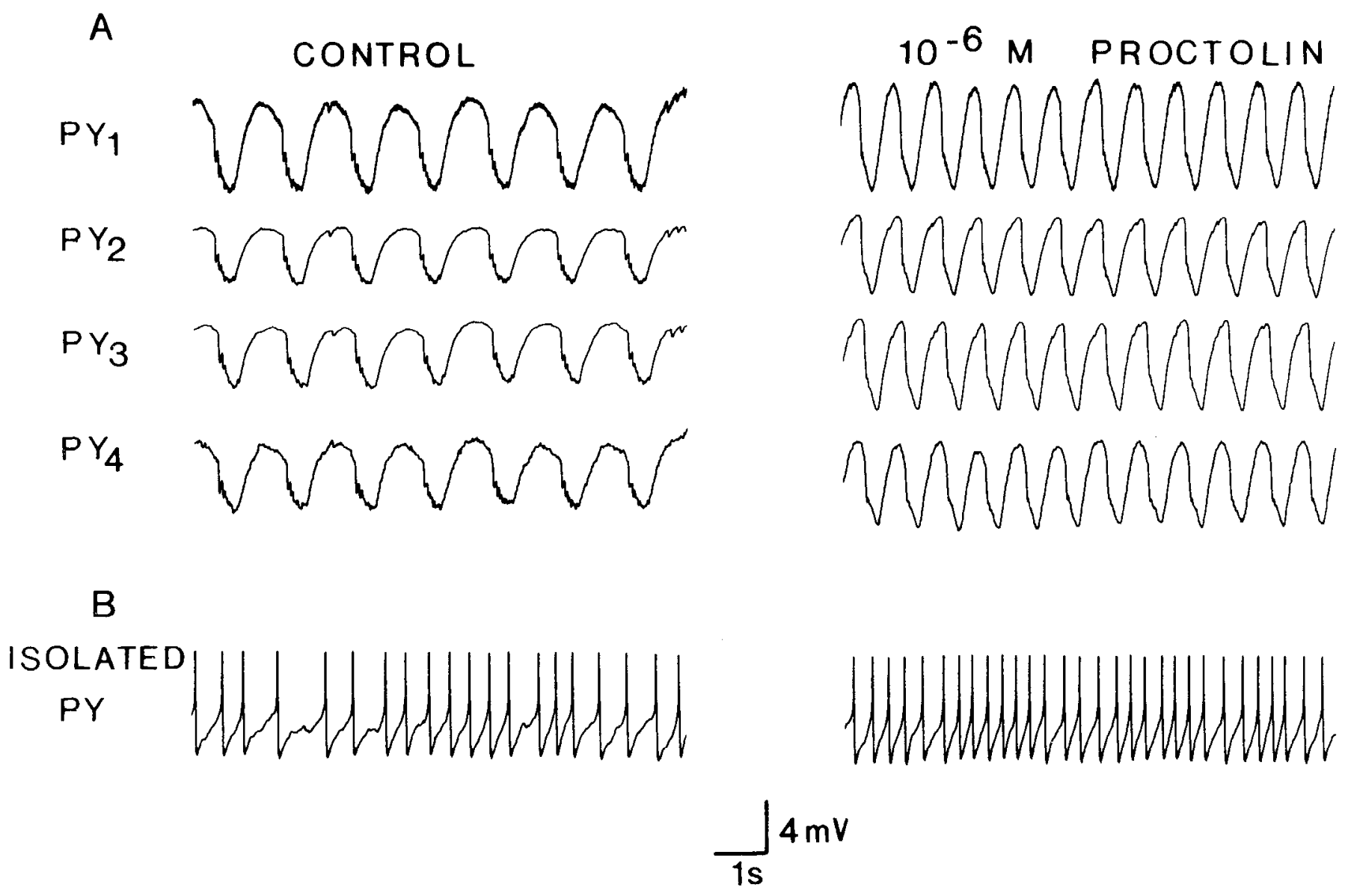

Figure 10. Proctolin does not change the activity of the PY neurons unless they are depolarized. $A$, Simultaneous intracellular recordings from the same $4 \mathrm{PY}$ neurons in saline (left) and in $10^{-6} \mathrm{M}$ proctolin (right). Proctolin increased the frequency and amplitude of the inhibitory inputs from the $\mathrm{AB}$ and $\mathrm{PD}$ neurons, but did not induce the PY neurons to fire action potentials. The most hyperpolarized point of membrane potential in these neurons in saline was as follows: $P Y_{1},-78 \mathrm{mV} ; P Y_{2},-46 \mathrm{mV} ; P Y_{3},-56 \mathrm{mV} ; P Y_{4},-64 \mathrm{mV}$. The resting potentials were unchanged in proctolin but the IPSPs were $2 \mathrm{mV}$ larger as a result of the increased AB/PD neuron activity. $B$, Activity of an isolated PY neuron depolarized to threshold by injecting current through a second electrode placed in the neuron. The application of $10^{-6} \mathrm{M}$ proctolin (right trace) in this case induced a slight depolarization of the neuron and increased its rate of firing action potentials. The most hyperpolarized points of membrane potential in this neuron were $-44 \mathrm{mV}$ (control) and $-42 \mathrm{mV}\left(10^{-6} \mathrm{M}\right.$ proctolin). PY neurons were isolated by photoinactivating the PD, VD, and LP neurons and applying saline containing $5 \times 10^{-6} \mathrm{M}$ PTX to block the AB-PY neuron glutamatergic synapse. Scale bars apply to both portions of the figure.

advantageous because the cycle frequencies were the same both in the presence and the absence of the LP neuron (see legend, Fig. 11). The top left panel of Figure 11 shows phase plots of the activities of the $A B, L P$, and VD neurons in saline; the top right panel shows these neurons in $10^{-6} \mathrm{M}$ proctolin. (The raw data from which these plots were derived are shown in Fig. 4.) While proctolin application did not greatly increase the burst length of the LP neuron, it did increase its frequency of action potential generation (Fig. 4). As usual, the VD neuron began to fire later in proctolin, the beginning of its burst moving from a phase of 0.42 to one of 0.65 . The bottom panels of Figure 11 show phase plots after photoinactivation of the LP neuron. In saline without the LP neuron, the VD neuron begins to fire immediately after (at phase 0.23 ) the $\mathrm{AB} / \mathrm{PD}$ neurons' bursts. This immediately suggests that the LP neuron is important in determining the phase of the beginning of the VD neuron burst. In proctolin after deletion of the LP neuron, the beginning of the VD neuron activity still shows a phase retardation (to 0.54 ). Thus, the increased activation of the AB neuron (and therefore its increased inhibition of the VD neuron) is responsible for some of the phase retardation of the beginning of the VD neuron burst in the presence of proctolin in the intact network. However, the fact that the phase retardation is only half that observed in the intact network argues further that the LP neuron is also important in this process.

In other experiments we placed 2 electrodes in the LP neuron and attempted to alter the firing time of the VD neuron in saline by depolarizing the LP neuron. These experiments revealed that rapid, large-amplitude depolarizations of the LP neuron that were timed to the end of the $\mathrm{AB} / \mathrm{PD}$ neuron burst effectively delayed the beginning, or interrupted an ongoing, VD neuron burst, but that tonic depolarizations of the LP neuron were not effective in delaying the VD neuron burst (data not shown). These observations provide a partial explanation for the large variability seen in the time of VD neuron firing in saline (note error bars on the VD neuron phase plot in the top panel of Fig. 3 ) since, as noted earlier in Results, the activity of the LP neuron in saline varies considerably in different preparations when the STG is removed from anterior inputs by sucrose block.

Pyloric frequency. There is a striking difference between the average frequency in proctolin of the intact network $(1.1 \pm 0.2$ $\mathrm{Hz})$ and that of the isolated $\mathrm{AB}$ neuron in proctolin $(2.1 \pm 0.3$ 
CONTROL
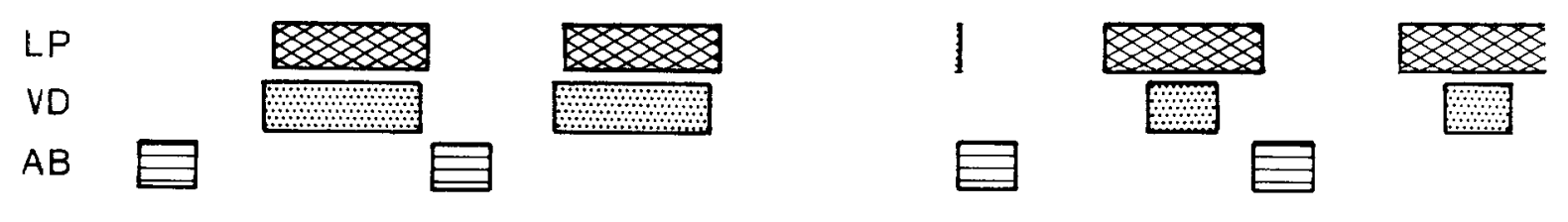

$10^{-6} M$ PROCTOLIN
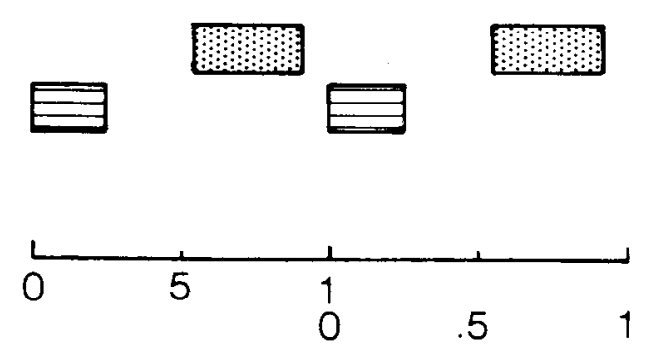

Figure 11. Role of the AB and LP neurons in controlling the VD neuron phase. Upper left, Phase-angle plot of the activities of the LP, VD, and $\mathrm{AB}$ neurons in control saline; upper right, their activities in $10^{-6} \mathrm{M}$ proctolin. The proctolin was then washed out and the LP neuron photoinactivated. Lower panels, Plots of the VD and AB neuron activities with the LP neuron deleted. Lower left, in saline; lower right, in 10 ${ }^{-6} \mathrm{M}$ proctolin. Pyloric cycle frequencies $(\mathrm{Hz}$ ) were 0.48 (top left); 0.43 (bottom left); 0.94 (top right), 0.93 (bottom right).

$\mathrm{Hz}$ ). The connectivity diagram shown in Figure 1 suggests several different explanations for the decrease in $\mathrm{AB}$ neuron frequency seen in the intact network. The increased inhibition of the PD and VD neurons by the LP neuron could inhibit the AB neuron via the electrical junctions between the PD, VD, and $\mathrm{AB}$ neurons. Alternatively, the $\mathrm{AB}$ neuron could be slowed down because it is electrically coupled to the VD and PD neurons, which are not responsive to proctolin. To determine the importance of these factors on the frequency that the intact network attains in $10^{-6} \mathrm{M}$ proctolin, we selectively deleted various individual neurons from the network and measured cycle frequency in proctolin.

The relative unimportance of the LP neuron in controlling cycle frequency is illustrated in Figure 12, which summarizes the results of a series of experiments in which proctolin was applied to the STG, the LP neuron was deleted, and proctolin reapplied. The clear bars show pyloric frequency in the absence of proctolin, and the hatched bars show the effect of the presence of proctolin. The left-hand pair in Figure 12 represents the STG before LP neuron deletion, and the right-hand pair after deletion of the LP neuron. The application of proctolin resulted in statistically significant ( $p<0.01$; repeated-measures ANOVA) increases in frequency as compared to saline values, both when the LP neuron was in the circuit and after it had been deleted. However, the frequencies with and without the LP neuron, either in saline (Fig. 12, first and third bars) or in the presence of proctolin (second and fourth bars), were not statistically different. Therefore the increased inhibition of the PD and VD ncurons by the LP neuron in proctolin does not appear to be a major contributing factor to the slower cycle frequency observed with the intact network in proctolin than with the isolated $A B$ neuron in proctolin.

The top panel of Figure 13 shows the average frequencies attained in proctolin by circuits in which various combinations of the electrically coupled VD and PD neurons were photoinactivated. It is apparent that deleting one or both of the PD neurons increases the frequency with which the remaining network cycles in the presence of proctolin. The contribution of the VD neuron is less clear, although deleting it does increasc the frequency, provided that at least one of the PD neurons is also deleted.

The bottom panel of Figure 13 shows the results of a series of experiments in which we (1) applied proctolin to the intact network, (2) photoinactivated neurons to reduce the set of the $A B, V D$, and PD neurons as marked under the bars, and (3) then reapplied proctolin. The frequency of the intact network in proctolin was subtracted from that of the reduced network; the bars in the bottom panel of Figure 13 show the averages of these differences. (These results are a subset of those in the top panel of Fig. 13, since those values include all cases in which we applied proctolin to reduced networks, whether or not we had first applied proctolin to the intact network.) The first bar in the bottom panel shows the differences between the frequencies in proctolin of intact networks and those with $A B$ and $P D$ neurons left (VD neuron deleted), and the second bar shows those differences between intact networks and those with the $A B, V D$, and a single PD neuron left (a single PD neuron deleted), etc. It is apparent that the deletion of any of the electrically coupled neurons results in an increase in cycle frequency, but that the PD neurons are more important in this process than is the VD neuron (compare the second bar in Fig. 13 to the first, and the fourth to the third).

Figure 14 is a summary connectivity diagram showing both the neurons directly affected by proctolin (horizontal hatching) and those whose activity is changed in the presence of proctolin (vertical hatching). Although 3 of the types of neurons respond to proctolin directly, only 2 of these, the AB and the LP neurons, actually change their activity. Of the 4 neuron types that change 


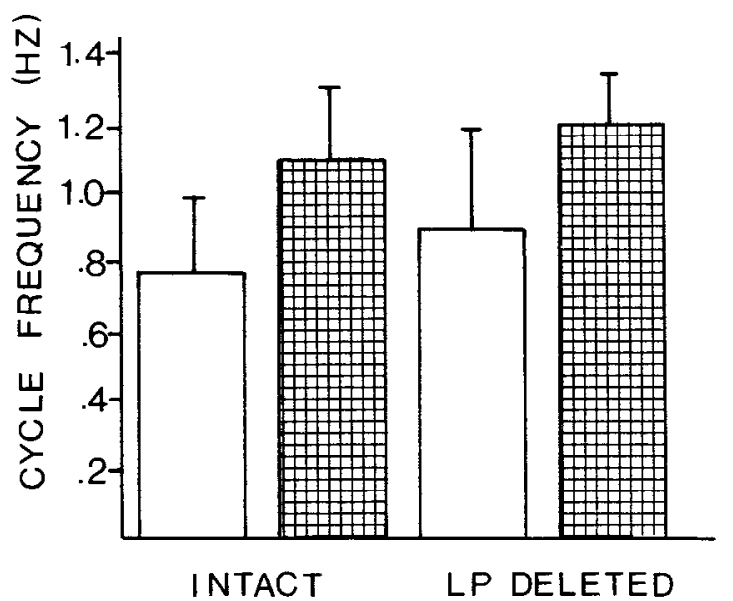

Figure 12. Deletion of the LP neuron does not affect the cycle frequency attained by the pyloric network in the presence of proctolin. A series of experiments was undertaken in which proctolin was applied to the STG, the LP neuron photoinactivated, and proctolin reapplied. First bar, Average pyloric frequency in saline before LP neuron deletion. Second bar, Average frequency in $10^{-6} \mathrm{M}$ proctolin before LP neuron deletion. Third bar, Average frequency in saline after LP neuron deletion. Fourth bar, Average frequency in $10^{-6} \mathrm{M}$ proctolin after LP neuron deletion. Error bars, SDs.
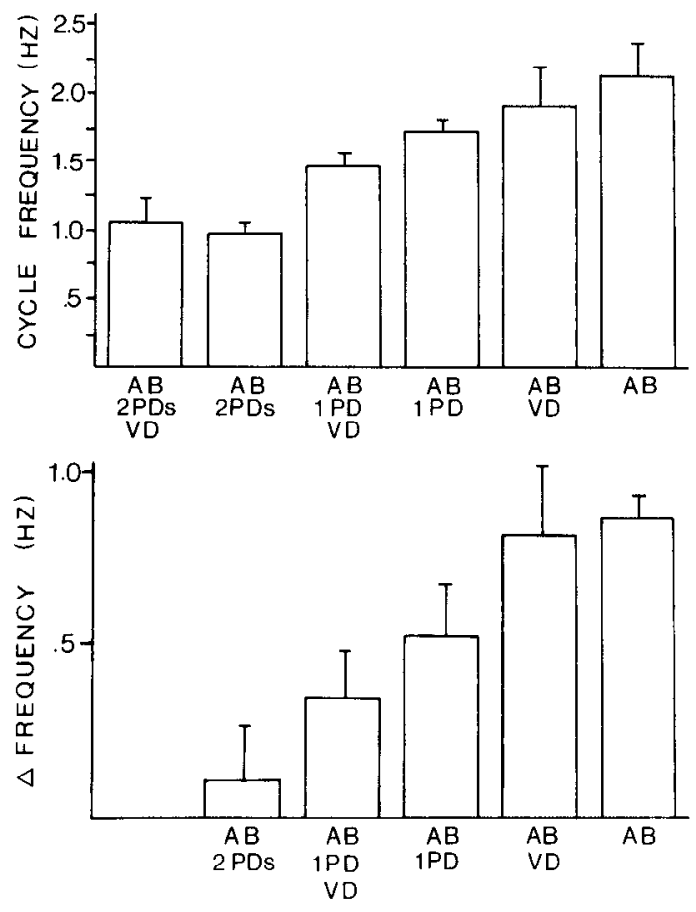

Figure 13. Deletion of the PD neurons has a dramatic effect on the cycle frequency attained by the pyloric network in the presence of proctolin. Top, Bar graph showing the average frequencies in proctolin of pyloric networks in which the listed neurons remain. Error bars are SD. Bottom, Proctolin was applied to the STG, one or more of the VD and PD neurons were photoinactivated, and proctolin reapplied. Bars are average differences between frequencies the networks achieved in proctolin in the intact state and attained in proctolin after the networks had been reduced to the one that contained the neurons listed under the bar. For each of these cases, the frequency differences between the intact and deleted condition are significantly different at the $p<0.01$ level (repeated-measures ANOVA). The different cases are statistically different from one another as follows: The fifth bar is different from the first, second, and third bars; the fourth bar is different from the first and second bars; and the third bar is different from the first bar $(p<0.05$; Student's $t$ test). Error bars, SDs.

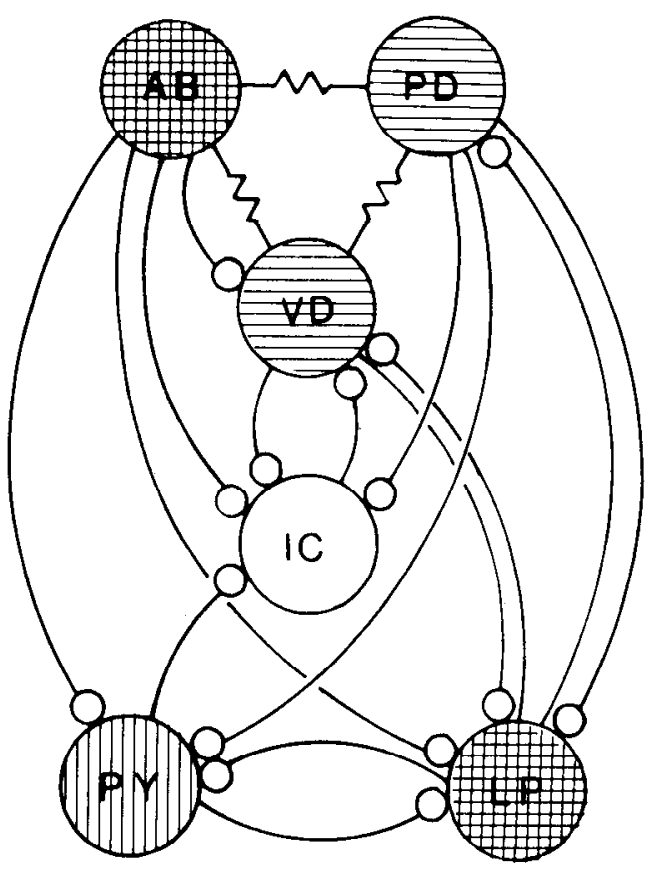

Figure 14. Proctolin actions on the pyloric network. Neurons directly affected by proctolin when isolated from all other pyloric neurons (AB, LP, and PY) contain vertical lines. Neurons whose activity changes when proctolin is applied to the circuit contain horizontal lines (AB, PD, LP, $\mathrm{VD})$. Those neurons directly affected and whose activity changes are cross-hatched ( $\mathrm{AB}$ and $\mathrm{LP}$ ). As in Figure 1, circles show inhibitory chemical synapses and resistor symbols denote electrical coupling.

their activity in the presence of proctolin, 2 of them, the PD and VD neurons, are not directly affected by proctolin. Both the $A B$ and $L P$ neurons are important in influencing the activity of the VD neuron. Finally, the frequency of the pacemaker $A B$ neuron is strongly modified by the PD neurons (and less so by the VD neuron) such that its burst frequency in proctolin in the intact network is half that attained in proctolin when isolated.

\section{Discussion}

Modulation of the output of neural networks by neuropeptides is important in increasing the flexibility of nervous systems. In this paper we have described the modulation of the pyloric network of lobsters by the neuropeptide proctolin. To understand how proctolin modulates the pyloric motor pattern, we have (1) characterized the effects of proctolin on those patterns, (2) characterized the effects of proctolin on the individual neurons that constitute the pyloric neural network, and (3) attempted to explain the effects of proctolin on this network on the basis of its known synaptic connectivity, and of the actions of proctolin on its component ncurons. The modulatory actions of proctolin on the pyloric rhythms are the result of direct proctolin action on only 2 of the network's neurons, one of which serves as the network's pacemaker. However, as a consequence of the synaptic connectivity of the pyloric network, the patterns of activity in neurons not directly responsive to proctolin are also altered. Moreover, those neurons not directly responsive alter the response to proctolin of neurons that are directly affected by proctolin. At least some of proctolin's actions are expressed in a voltage-dependent manner, and this has important consequences for integration in the network. 


\section{Proctolin and isolated neurons}

Proctolin is capable of inducing bursting in the AB neuron, the rhythmic pacemaker of the pyloric neural network. Proctolin also increases the amplitude and frequency of the oscillations of isolated, active AB neurons. Previous work has shown that the muscarinic agonist pilocarpine and the amines serotonin, dopamine, and octopamine can also activate $\mathrm{AB}$ neuron bursts (Marder and Eisen, 1984b; Flamm and Harris-Warrick, 1986a, b; Harris-Warrick, 1987). Proctolin's excitatory actions on the AB neuron, unlike those of pilocarpine and dopamine (Raper, 1979a, b; Anderson, 1980), but similar to those of serotonin and octopamine (R. M. Harris-Warrick, personal communication) were blocked by TTX.

Proctolin's excitatory cffects on LP and PY neurons were expressed only if these neurons were at threshold or more depolarized. This suggests that the final consequence of proctolin action might be to modulate one (or more) of the voltage-dependent conductances in these neurons, such as has been shown to occur in many other systems with peptides (Dunlap and Fischbach, 1981; Nowak and MacDonald, 1981; Adams et al., 1983; Cottrell et al., 1984; Jones, 1985). One possibility (of many) is that proctolin modulates the activity of a low-threshold $\mathrm{Na}^{+}$or $\mathrm{Ca}^{2+}$ channel, such as those described by Gilly and Armstrong (1984) and Matteson and Armstrong (1986). Schwarz et al. (1980) and Kravitz et al. (1980) reported a voltage and $\mathrm{Ca}^{2+}$ sensitivity in proctolin's effects on a crustacean muscle and suggested that proctolin might activate voltage-sensitive $\mathrm{Ca}^{2+}$ entry at the resting level of membrane potential (as might be occurring in the STG). However, Sullivan and Miller (1984) showed that proctolin's actions on crustacean cardiac ganglion neurons are TTX resistant and may be due to a decrease in a resting $\mathrm{K}^{+}$conductance. Interestingly, the STG of the crab Cancer borealis shows TTX-resistant, proctolin-induced depolarizing conductance decreases (J. Golowasch and E. Marder, unpublished observations), which may be similar to the responses of Sullivan and Miller (1984). Thus, pharmacologically different postsynaptic responses may be involved in different target tissues and in different species.

Our results are consistent, for several reasons, with the possibility that proctolin's actions on STG neurons might involve some kind of second messenger system. First, the effects of proctolin outlast its presence by many minutes, or even hours. Second, when proctolin was applied to hyperpolarized isolated LP neurons, although no changes in membrane potential or input resistance were seen during application, the normal proctolin activation was seen when the neuron was released from hyperpolarization. Third, the $\mathrm{Ca}^{2+}$ dependence of proctolin's actions on STG neurons could result from its involvement as a second messenger. In a number of other systems, proctolin's effects also have very low threshold concentrations, are $\mathrm{Ca}^{2+}$ dependent, are of long duration, and are achieved without consistent changes in membrane potential or input resistance (Brown, 1975; Lingle, 1979; Benson ct al., 1981; Adams and O'Shea, 1983; Watson et al., 1983; Rane et al., 1984; Cook and Holman, 1985); they may also be mediated through a second messenger system involving $\mathrm{Ca}^{2+}$ (Dunbar and Huddart, 1982) or cAMP (Hiripi et al., 1979; Jennings et al., 1983; Evans, 1984). However, no consensus emerges as to whether cyclic AMP or $\mathrm{Ca}^{2+}$ is involved as second messenger, or even as to whether proctolin opens or modifies a $\mathrm{Ca}^{2}$ conductance. Thus, while many of these effects are similar to our own observations, the variability among them leads us to argue that proctolin can have different postsynaptic effects, just as do the effects and mechanisms of other, more studied, neurotransmitters (Kehoe and Marder, 1976).

The PD neurons are electrically coupled to the AB neuron and depolarize synchronously with it. However, isolated PD neurons are not sensitive to proctolin. Thus proctolin, like dopamine and serotonin (Mardcr and Eisen, 1984b; Flamm and Harris-Warrick, 1986a, b; Harris-Warrick, 1987), has different effects on the AB neuron and the PD neurons. We have shown, by several criteria, that the PD, VD, and IC neurons are unresponsive to proctolin. One particularly compelling observation was that the behavior of the unresponsive neurons did not change when proctolin was applied, even when they were depolarized above threshold (which reveals proctolin's effects in the LP and PY neurons). We also directly measured the coupling coefficients among the PD and VD neurons and observed no change due to proctolin (data not shown). Since the sites of coupling are located in the neuropil, this is also a sensitive test for any changes in the input impedance of these neurons, and this result supports the contention that these neurons are unresponsive to proctolin.

\section{Physiological relevance of proctolin actions}

Proctolin induced dramatic changes in the pattern produced by the pyloric network when isolated from anterior inputs from the CGs and EG. It is quite possible that proctolin's effects will be somewhat different when anterior inputs to the STG are left intact and under conditions in which the PY neurons depolarize above threshold during pyloric cycling.

Bath-applications of proctolin may be mimicking its effects when naturally released. Recent work in the STG of $C$. borealis suggests that stimulation of a proctolin containing EG neuron produces effects on the pyloric rhythm similar to those produced by proctolin (Nusbaum and Marder, 1987). Also, neuropeptides may act as local hormones, diffusing from their release sites to receptors on neurons located many microns away (Jan and Jan, 1982). The anatomy of the STG is extremely appropriate for this type of release, as it is tightly surrounded by a sheath and its neuropil is densely and widely filled with proctolin-containing fibers (Marder et al., 1986). Heinzel and Selverston (1985) have shown that the injection of proctolin into the hemolymph has the same effects on the movements of the gastric mill region of the stomach as are predicted from applying proctolin to the isolated STG. This suggests that it may be valid to extrapolate from the neural output of the pyloric network to the motion of the pyloric region. If so, proctolin would serve, in the intact animal, to increase the frequency and vigor of the movements of the pylorus. Proctolin enhances the tension generated by certain of the stomatogastric muscles (Lingle, 1979), as well as activating the pyloric and gastric neural networks. It may thus serve as a general excitor of stomach activity. It will be interesting to see if proctolin also activates the esophageal and cardiac sac networks, 2 other neural networks involved in generating motions of the stomach.

\section{Proctolin and the pyloric pattern}

The first point to consider is the concentration dependence of proctolin's effects on the intact pyloric network. The AB and LP neurons may have a different dose-response relationship and threshold for proctolin (Figs. 6 and 8). Harris-Warrick (1987) suggests that neural networks containing neurons with different 
dose-response relationships to the same neuromodulatory substance could allow a single neuromodulatory substance to induce different modifications in the output of a neural network, depending on the effective concentration of the neuromodulator released. Moreover, Flamm and Harris-Warrick (1986a) have shown that dopamine and octopamine each induce different stable pyloric motor patterns at different concentrations. While our data suggest that the $\Lambda \mathrm{B}$ neuron could be activated by $\mathrm{cx}$ tremely low concentrations of proctolin without the LP neurons being affected (Figs. 6, 8), it is not possible to assess the physiological relevance of this observation. The data on pyloric frequency and phase suggest, however, a graded and smooth transition in the pattern from $10^{-8}$ to $10^{-6} \mathrm{M}$ proctolin (Fig. 3), arguing that proctolin is inducing similar changes in the motor pattern throughout this concentration range.

The primary effects of proctolin on the pyloric motor patterns are (1) an increase in the burst length and number of spikes per burst of the LP neuron, (2) an increase in pyloric frequency, and (3) a phase retardation of the beginning of VD neuron activity and a decrease in the number of VD neuron spikes per burst. The increased burst length and frequency of the LP neuron can be most simply explained as a result of proctolin's direct excitatory effects on the LP neuron. It is possible that the increased inhibition from the $\mathrm{AB}$ and $\mathrm{PD}$ neurons also plays a role, as postinhibitory rebound is known to be important to the activities of these neurons. We are unable to test the significance of this effect, however, since, if we photoinactivate the $A B$ neuron, pyloric cycling ceases. At least, in this case, it is not necessary to invoke "circuit" actions to explain the observed changes, though they may play a role.

Proctolin increases the frequency of the intact pyloric rhythm. However, the average frequency in proctolin of the intact pyloric network is about $1 \mathrm{~Hz}$, while that of the isolated $A B$ neurons is more than $2 \mathrm{~Hz}$. Deletion of the LP neuron showed that the slowing of the $\mathrm{AB}$ neuron when in the pyloric network is not due to the LP neuron's increased activity, but results instead from the "drag" of the PD and VD neurons, which are electrically coupled to the AB neuron. Therefore, this slowing of the $A B$ neuron in the intact network arises from "circuit" interactions between the directly affected $A B$ neuron and neurons unaffected by proctolin. Thus, although the $A B$ neuron serves as the rhythmic pacemaker of the pyloric network, it cannot be considered the sole source of frequency control.

Proctolin, pilocarpine, serotonin, dopamine, and octopamine all directly affect the pacemaker AB neuron (Marder and Eisen, 1984b; Flamm and Harris-Warrick, 1986a, b; Harris-Warrick, 1987). Only pilocarpine application results in frequencies of intact pyloric cycling similar to those attained by isolated AB neurons. Pilocarpine also induces cyclic behavior in isolated PD neurons (Marder and Eisen, 1984b). Therefore the PD and VD neurons may serve as frequency governors in this system, slowing the $\mathrm{AB}$ neuron unless they are also excited. In principle, excitation of the PD neurons alone could result in an increase in pyloric cycle frequency. The fact that none of the known excitatory neurotransmitters exerts its effects through this mechanism suggests, however, that frequency modulation of this system always involves at least the $A B$ neuron.

The isolated VD neuron is unaffected by proctolin, but the beginning of its burst is retarded in proctolin as a result of the increased activity in the AB and LP neurons. The control of the VD neuron phase is particularly interesting, as it shows considerable variability both when the pyloric network is isolated (Fig.
3) and when anterior inputs are present (unpublished observations). Prior work demonstrated that the inhibitory synaptic inputs from both the $A B$ and LP neurons are important in determining the VD neuron phase in normal pyloric cycling (Miller and Selverston, 1982b). Nagy and Dickinson (1983) have demonstrated that input from a defined modulatory interneuron in the lobsters Jasus lalandii and Palinurus vulgaris can advance the phasc of the beginning of the VD neuron's activity by weakening the effective strength of the $\mathrm{AB}$ neuron's inhibition of the VD neuron. We have shown that another putative modulator of the pyloric system, proctolin, instead phase-retards the beginning of the VD neuron's burst as a result of increased AB and LP neuron activity (see also Eisen and Marder, 1984). The physiological significance of these phase shifts is unknown. It is clear that the VD neuron's position in the pyloric network allows considerable control of the phase of its bursts.

\section{Proctolin and interactions between gastric and pyloric thythms}

Although pyloric and gastric rhythms are generated by different neurons and move different muscles, proctolin applications can strongly influence both rhythms (Hooper and Marder, 1984; Heinzel and Selverston, 1985; Marder and Hooper, 1985; Marder et al., 1986). In $P$. interruptus there are weak interactions between the gastric and pyloric systems (Mulloncy, 1977). Subsequent to application of high proctolin concentrations, it is not uncommon to see strong interruptions or disruptions of normal pyloric rhythms that may be associated with gastric or cardiac sac activity. However, the synaptic connections responsible for these interactions are not known. These interruptions were usually seen with a much longer latency after proctolin application than that of activation of the pyloric rhythm, so we were able, in this study, to examine pyloric activations uncontaminated by these other effects, which have long cycle periods (several to many seconds) and are therefore easy to distinguish from direct actions on the pyloric system.

\section{Nonresponsive neurons are also important}

Earlier work on the pyloric system showed that pyloric rhythmicity derives from the pacemaker activity of the $A B$ neuron and is also an emergent property of the synaptic connectivity and membrane properties of the other neurons (Miller and Selverston, 1982a, b). We similarly find that proctolin's modulation of this network cannot be explained solely on the basis of its direct effects on isolated pyloric neurons. Instead, nonaffected neurons, by virtue of their synaptic connectivity to directly affected ones, both indirectly respond to proctolin and modify the responses of the directly affected neurons. This has several implications. First, one of the implicit assumptions of neuropharmacology is that understanding the distribution of receptors for a neurotransmitter or neurohormone will eventually lead to an understanding of the function of the substance. However, neurons that do not have proctolin receptors shape the physiological responses of neurons that do. This complicates facile predictions from receptor and transmitter distribution data concerning the consequence of activating pathways or parts of neural circuits. Second, some of the synaptic relations and membrane properties of these neurons might exist solely to allow modulatory inputs to have their effects. That is, the complexity of this network and its neurons may be greater than is required to produce the minimal pattern observed in isolated STG in saline, because this network also has built into it the ability to respond to difterent inputs by producing different outputs (Eisen and Marder, 1984; 
Marder and Hooper, 1985; Marder et al., 1986). Third, we speculate that these modulatory inputs are designed to change the output of the entire network and thus its motor patlern, not merely the output of individual neurons of that network. Thus, the functional target of modulatory inputs may be thought of as the entire neural network, not the network's individual neurons.

\section{Integrative consequences of the voltage-dependent expression of proctolin's actions}

The voltage-dependent expression of proctolin's effects on the LP and PY neurons has 2 consequences. First, this voltagedependent expression maintains the effectiveness of inhibitory input to these neurons despite proctolin's robust excitatory effects. When the gastric rhythm is active in saline, gastric-induced modulation of the pyloric system inhibits firing of the LP neuron, although pyloric timed IPSPs continue in the LP neuron during these periods. In spite of the strong excitatory effects of proctolin on the LP neuron, this modulation still occurs in proctolin. The voltage sensitivity of the proctolin effect can explain this observation as follows: No matter when in the pyloric cycle the gastric system inhibitory input begins, at some point the LP neuron oscillates to a subthreshold membrane potential as a result of its inhibition by the $\mathrm{PD}$ and $\mathrm{AB}$ neurons. In this range of membrane potential the excitatory effects of proctolin are not expressed. As long as the inhibitory input from the gastric system keeps the neuron below threshold, proctolin's excitatory actions will not be expressed. Any inhibitory input that lasts for several pyloric cycles and is strong enough to keep the LP neuron even a few millivolts below threshold in saline is sufficient to block its activity in proctolin as well (despite the strong excitatory proctolin action on the $L P$ neuron). Therefore, as a result of the voltage dependence of the proctolin effects, it can induce dramatic excitation of a ncuron whilc preserving its responsiveness to even weak inhibitory inputs. The pyloric network is known to receive multiple inputs from other parts of the nervous system; the fact that proctolin's excitatory effects are expressed only at threshold or greater depolarization may be profoundly inportant in maintaining the effectiveness of these inputs in spite of proctolin's excitation of the pyloric network.

Second, neurons that depend on other excitatory inputs for activation above threshold can be switched in and out of the network in the presence of proctolin, although proctolin acts on them. The PY neurons are a likely example. Presumably, when the anterior inputs from the CGs and EG are intact, one or more of these inputs activates the PY neurons during pyloric cycling (Fig. 1). Under these conditions, proctolin application should result in an increase in PY neuron activity, since the PY neurons will then depolarize above the critical potential for the expression of proctolin's excitatory effects during each pyloric cycle. However, when the central inputs are inactive (as in our experiments), the PY neurons no longer rise above this critical potential, and so proctolin's excitatory effects are not expressed. In a way, this is the converse of the point mentioned above. Instead of the effectiveness of inhibitory input being maintained, the requirement for excitatory input is maintained. Thus, the vol lage-dependence of the proctolin effect is well suited for the task of providing strong excitation to the whole pyloric neural network without disrupting the effectiveness of its intrinsic synaptic connections or those of inputs from the rest of the nervous system.

\section{References}

Adams, M. E., and M. O'Shea (1983) Peptide co-transmitter at a neuromuscular junction. Science $221: 286-289$.

Adams, P. R., D. A. Brown, and S. W. Jones (1983) Substance P inhibits the M-current in bullfrog sympathetic neurones. Br. J. Pharmacol. 79: 330-333.

Anderson, W. W. (1980) Synaptic mechanisms generating nonspiking network oscillations in the stomatogastric ganglion of the lobster, Panulirus intermptus. Ph.D. dissettation, University of Oregon.

Benson, J. A., R. E. Sullivan, W. H. Watson, III, and G. J. Augustine, Jr. (1981) The pentapeptide proctolin acts directly on Limulus cardiac muscle to increase the amplitude of contraction. Brain Res. 213: 449-454.

Bidaut, M. (1980) Pharmacological dissection of pyloric network of the lobster stomatogastric ganglion using picrotoxin. J. Neurophysiol. 44: $1089-1101$.

Brown, B. E. (1975) Proctolin: A peptide transmitter candidate in insects. Life Sci. 17: 1241-1252.

Bruning, J. L., and B. L. Kintz (1977) Computational Handbook of Statistics, 2nd Ed., Scolt, Foresman, Glenview, IL.

Cook, B. J., and G. M. Holman (1985) The role of proctolin and glutamate in the excitation-contraction coupling of insect visceral muscle Comp. Biochem. Physiol. 80C: 65-73.

Cottrell, G. A., N. W. Davies, and K. A. Green (1984) Multiple actions of a molluscan cardioexcitatory neuropeptide and related peptides on identified Helix neurones. J. Physiol. (Lond.) 356: 315-333.

Dunbar, S. J., and H. Huddart (1982) Calcium movements in insect visceral muscle. Comp. Biochem. Physiol. 7/A: 425-438.

Dunlap, K., and G. D. Fischbach (1981) Neurotransmitters decrease the calcium conductance activated by depolarization of embryonic chick sensory neurones. J. Physiol. (Lond.) 317: 519-535.

Eisen, J. S. and E. Marder (1982) Mechanisms underlying pattern generation in lobster stomatogastric ganglion as determined by selective inactivation of identified neurons. IIl. Synaptic connections of electrically coupled pyloric neurons. J. Neurophysiol. 48: 1392-1415.

Eisen, J. S., and E. Marder (1984) A mechanism for the production of phase shifts in a pattern generator. J. Neurophysiol. $5 /: 1374-$ 1393.

Evans, P. D. (1984) Studies on the mode of action of octopamine, 5 -hydroxytryptamine and proctolin on a myogenic rhythm in the locust. J. Exp. Biol. II0: $231-251$.

Flamm, R. E., and R. M. Harris-Warrick (1986a) Aminergic modulation in the lobster stomatogastric ganglion. I. Effects on the motor pattern and activity of neurons within the pyloric circuit. J. Neurophysiol. 55: 847-865.

Flamm, R. E. and R. M. Harris-Warrick (1986b) Aminergic modulation in the lobster stomatogastric ganglion. II. Target neurons of dopamine, octopamine, and serotonin within the pyloric circuit. J. Neurophysiol. 55: 866-881.

Gilly, W. F, and C. M. Armstrong (1984) Threshold channels-A nove] type of sodium channel in squid giant axon. Nature $309: 448-450$.

Gola, M., and A. Selverston (1981) Ionic requirements for bursting activity in lobster stomatogastric neurons. J. Comp. Physiol. 145: $191-207$.

Harris-Warrick, R. M. (1987) Chemical modulation of central pattern generators. In Neural Control of Rhythmic Movements, A. H. Cohen, S. Rossignol, and S. Grillner, eds., Wiley, New York. (in press).

Hartline, D. K. (1979) Pattern generation in the lobster (Pamulins) stomatogastric ganglion. Il. Pyloric network simulation. Biol. Cybern. 33: $223-236$.

Hartline, D. K. (1987) Modeling stomatogastric ganglion. In The Crustacean Stomatogastric Nervous System: A Model for the Study of Central Nervous Systems, A. I. Selverston and M. Moulins, eds., pp. 181203, Springer-Verlag, Heidelberg.

Hartline, D. K., and D. V. Gassie (1979) Pattern generation in the iobster (Panulirus) stomatogastric ganglion. I. Pyloric neuron kinetics and synaptic interactions. Biol. Cybern. 33: 209-222.

Hartline, D. K., D. V. Gassie, and C. D. Sirchia (1987) PY cell types in the stomatogastric ganglion of Panulirus. In The Crustacean Stomatogastric Nervous System: A Model for the Study of Central Nenous Systems, A. I. Selverston and M. Moulins, eds., pp. 75-77, SpringerVerlag, Heidelberg.

Heinzel, H.-G., and A. I. Selverston (1985) Proctolin modulation of 
the gastric oscillator in the lobster stomatogastric ganglion. Soc. Neurosci. Abstr. 11:478

Hiripi, L., K. S. Rozsa, and T. A. Miller (1979) The effect of proctolin on the adenylate and guanylate cyclases in the Locusta brain at various developmental stages. Experientia 35: 1278-1288.

Hooper, S. L., and E. Marder (1984) Modulation of a central pattern generator by two neuropeptides, proctolin and FMRFamide. Brain Res. 305: 186-191.

Hooper, S. L., and E. Marder (1985) Neuronal targets of the modulatory action of proctolin on the pyloric system of the stomatogastric ganglion of Panulirus interrupins. Soc. Neurosci. Abstr. 11: 478.

Jan, L. Y., and Y. N. Jan (1982) Peptidergic transmission in sympathetic ganglia of the frog. J. Physiol. (Lond.) 327: 219-246.

Jennings, K. R., R. W. Steele, and A. N. Starratt (1983) Cyclic AMP actions on proctolin- and neurally-induced contractions of the cockroach hindgut. Comp. Biochem. Physiol. 74C: 69-74.

Jones, S. W. (1985) Muscarinic and peptidergic excitation of bull-frog sympathetic neurones. J. Physiol. (Lond.) 366: 63-87.

Kehoe, J. S., and E. Marder (1976) Identification and effects of neural transmitters in invertebrates. Annu. Rev. Pharmacol. Toxicol. 16: 245-268.

Kravili, E. A., S. Glusman, R. M. Harris-Warrick, M. S. Livingstone, T. Schwarz, and M. F. Goy (1980) Amines and a peptide as neurohormones in lobsters: Actions on neuromuscular preparations and preliminary behavioral studies. J. Exp. Biol, 89: 159-175.

Lingle, C. J. (1979) The effects of acetylcholine, glutamate, and biogenic amines on muscle and neuromuscular transmission in the stomatogastric system of the spiny lobster, Panulirus interruptus. Ph.D. thesis, University of Oregon.

Marder, E. (1984) Mechanisms underlying neurotransmitter modulation of a neuronal circuit. Trends Neurosci. 7: 48-53.

Marder, E., and J. S. Eisen (1984a) Transmitter identification of pyloric neurons: Electrically coupled neurons use different transmitters. J. Neurophysiol. $51: 1345-1361$.

Marder, E., and J. S. Eisen (1984b) Electrically coupled pacemaker neurons respond differently to the same physiological inputs and neurotransmitlers. J. Neurophysiol. 5I: 1362-1373.

Marder, E., and S. L. Hooper (1985) Neurotransmitter modulation of the stomatogastric ganglion of decapod crustaceans. In Model Neural Networks and Behavior, A. I. Selverston, ed., pp. 319-337, Plenum, New York.

Marder, E., S. L. Hooper, and K. Siwicki (1986) Innervation and modulation of the stomatogastric ganglion of decapod crustaceans by the neuropeptide, proctolin. I. Comp. Neurol. 243: 454-467.

Matteson, D. R., and C. M. Armstrong (1986) Properties of two types of calcium channels in clonal pituitary cells. J. Gen, Physiol. 87: 161182

Miller, J. P. (1987) Pyloric mechanisms. In The Crustacean Stomatogastric Nervous System: A Model for the Study of Central Nervous Systeris, A. I. Selverston and M. Moulins, eds., pp. 109-136, Springer-Verlag, Heidelberg.

Miller, J. P., and A. L. Selverston (1979) Rapid killing of single neurons by irradiation of intracellularly injected dye. Science $206: 702-704$.

Miller, J. P., and A. I. Selverston (1982a) Mechanisms underlying pattern generation in lobster stomatogastric ganglion as determined by selective inactivation of identified neurons. II. Oscillatory properties of pyloric neurons. J. Neurophysiol. 48: 1378-139 h.

Miller, I. P., and A. I. Selverston (1982b) Mechanisms underlying pattern generation in lobster stomatogastric ganglion as determined by selective inactivation of identified neurons. IV. Network properties of pyloric system. J. Neurophysiol. 48: 1416-1432.
Mulloney, B. (1977) Organization of the stomatogastric ganglion of the spiny lobster. V. Coordination of the gastric and pyloric systems J. Comp. Physiol. 122: 227-240.

Mulloney, B., and A. I. Selverston (1974) Organization of the stomatogastric ganglion in the spiny lobster. I. Neurons driving the lateral teeth. J. Comp. Physiol. 91: 1-32.

Nagy, F., and P. S. Dickinson (1983) Control of a central pattem generator by an identified modulatory interneuronc in crustacea. I Modulation of the pyloric motor output. J. Exp. Biol. 105: 33-58.

Nagy, F., and J. P. Miller (1987) Pyloric pattern generation in Panulirus interruptus is terminated by blockade of activity through the stomatogastric nerve. In The Crustacean Stomatogastric Nervous System: $A$ Model for the Study of Central Nervous Systems, A. I. Selverston and M. Moulins, eds., pp. 136-139, Springer-Verlag, Heidelberg.

Nowak, L. M., and R. L. MacDonald (1981) Substance P decreases a potassium conductance of spinal cord neurons in cell culture. Brain Res. 214: 416-423.

Nusbaum, M. P. and E. Marder (1987) An identified, proctolin-containing neuron (MPN) modulates the pyloric rhythm in the crab Cancer borealis. Soc. Neurosci. Abstr. (in press).

O'Shea, M., and M. Schaffer (1985) Neuropeptide function: The invertebrate contribution. Annu. Rev. Ncurosei. 8: 171-198.

Rane, S. G., P. H. Gerlach, and G. A. Wyse (1984) Neuromuscular modulation in Limulus by both octopamine and proctolin. J. Neurobiol. 15: 207-220.

Raper, J. A. (1979a) Non-impulse mediated synaptic transmission in the stomatogastric ganglion of the spiny lobster. Ph.D. thesis, University of Califomia, San Diego.

Raper, J. A. (1979b) Nonimpulse-mediated synaptic transmission during the generation of a cyclic motor program. Science 205: 304-306.

Rezer, E., and M. Moulins (1983) Expression of the crustacean pyloric pattern generator in the intact animal. J. Comp. Physiol. 153: 17-28.

Russell, D. F. (1976) Rhythmic excitatory inputs to the lobster stomatogastric ganglion. Brain Res. 101: 582-588.

Russell, D. F. and K. Graubard (1987) Cellular and synaptic propcrtics. In The Crustacean Stomatogastric Nervous System: A Model for the Study of Central Nervous Systems, A. I. Selverston and M. Moulins, eds, pp. 79-100, Springer-Verlag, Heidelberg.

Russell, D. F., and D. K. Hartline (1982) Slow active potentials and bursting motor patterns in pyloric network of the lobster, Panulirus interruptus. J. Neurophysiol. 48: 914-937.

Schwarz, T. L., R, M. Harris-Warrick, S. Glusman, and E. A. Kravitz (1980) A peptide action in a lobster neuromuscular preparation. J. Neurobiol. 11: 623-628.

Selverston, A. I., and J. P. Miller (1980) Mechanisms underlying pattern generation in lobster stomatogastric ganglion as determined by selective inactivation of identified neurons. I. Pyloric system. J. Neurophysiol. 44: 1102-1121.

Selverston, A. I., D. F. Russell, J. P. Miller, and D. G. King (1976) The stomatogastric nervous system: Structure and function of a smal] neural network. Prog. Neurobiol. 7: 215-290.

Siwicki, K. K, and C. A. Bishop (1986) Mapping of proctolin-like immunoreactivity in the nervous system of lobster and crayfish. J. Comp. Neurol. 243: 435-453.

Sullivan, R. E., and M. W. Miller (1984) Dual effects of proctolin on the rhythmic burst activity of the cardiac ganglion. J. Neurobiol. 15 : $173-196$.

Watson, III, W. H., G. J. Augustine, J. A. Benson, and R. E. Sullivan (1983) Proctolin and an endogenous proctolin-like peptide enhance the contractility of the Limulus heart. J. Exp. Biol. 103: 55-73. 